\title{
The Historical Trauma and Resilience of Individuals of Mexican Ancestry in the United States: A Scoping Literature Review and Emerging Conceptual Framework
}

\author{
Araceli Orozco-Figueroa
}

Citation: Orozco-Figueroa, Araceli. 2021. The Historical Trauma and Resilience of Individuals of Mexican Ancestry in the United States: A Scoping Literature Review and Emerging Conceptual Framework. Genealogy 5: 32. https://doi.org/ 10.3390/genealogy5020032

Received: 29 September 2020

Accepted: 22 March 2021

Published: 29 March 2021

Publisher's Note: MDPI stays neutral with regard to jurisdictional claims in published maps and institutional affiliations.

Copyright: (C) 2021 by the author. Licensee MDPI, Basel, Switzerland. This article is an open access article distributed under the terms and conditions of the Creative Commons Attribution (CC BY) license (https:// creativecommons.org/licenses/by/ $4.0 /)$.
School of Social Work, University of Washington, 410115 Avenue NE Seattle, WA 98105-6250, USA; aorozco@uw.edu

\begin{abstract}
Recently, Black, Indigenous, and other People of Color (BIPOC) have encountered an escalation in adverse social conditions and trauma events in the United States. For individuals of Mexican ancestry in the United States (IMA-US), these recent events represent the latest chapter in their history of adversity: a history that can help us understand their social and health disparities. This paper utilized a scoping review to provide a historical and interdisciplinary perspective on discussions of mental health and substance use disorders relevant to IMA-US. The scoping review process yielded 16 peer reviewed sources from various disciplines, published from 1998 through 2018. Major themes included historically traumatic events, inter-generational responses to historical trauma, and vehicles of transmission of trauma narratives. Recommendations for healing from historical and contemporary oppression are discussed. This review expands the clinical baseline knowledge relevant to the diagnosis, treatment, and prevention of contemporary traumatic exposures for IMA-US.
\end{abstract}

Keywords: scoping review; Mexican and Mexican-Indigenous; historical trauma and posttraumatic growth framework (HT-PGF); historical trauma events (HTEs); behavioral health; resilience; institutional mistrust; health-advantage; wellness; stronger together

\section{Introduction}

The current political climate engenders adverse social conditions for several populations, including Black, Indigenous, and other People of Color (BIPOC). For individuals of Mexican ancestry in the United States (IMA-US) these social conditions have worsened in the last few years. IMA-US are by far the single largest U.S. immigrant group by nationality, and their access to satisfactory social and healthcare services has been historically inadequate (González de Alba 2010; Satcher 2000; Stepler and Brown 2016). Repeatedly, they have been the target of anti-immigrant sentiment and political violence (Greene 2018). A vivid example of this involves the conditions of homeland security detention centers in which people with real or perceived Mexican ancestry have been held. They were not provided standard sanitation resources, the children were held in cages, and their parents were frequently deported without any plan for reunification (Greene 2018; Hernández 2019). These recent attacks on the physical and psychological integrity of IMA-US represent the latest chapter in their history of adversity. Knowing this history can help us to better understand the structural systems that have enabled and maintained their social and health disparities.

\subsection{Purpose}

The purpose of this article is to identify, evaluate, and integrate the scholarly work that uses a historical perspective to examine the behavioral health of IMA-US, including mood and substance use disorders (SUDs). An overview of the nature and scope of the selected literature is presented, and the emerging conceptual framework introduced by 
this scholarship is contextualized in terms of contemporary and historical social discourses. The population demographic profile is first introduced, which is followed by a summary of their risk and protective factors for behavioral health problems. The strengths and limitations of prior research are discussed to justify the need for a new conceptual direction. The proposed conceptualization (1) traces the onset of the health disparities of IMA-US to Historical Traumatic Events (HTEs), (2) recounts the impacts from these events for several subgroups within this population, (3) describes both maladaptive and resilient responses that stem from such exposures, (4) identifies vehicles/modalities through which narratives of mass trauma are transmitted, and (5) presents recommendations for recovery from historical trauma (HT).

\subsection{Contribution of This Review \& Overview of the Selected Literature}

This article is the first to compile the literature that discuss mental and substance use disorders of IMA-US in the context of the population's lifetime trauma. A variety of disciplines are represented in these sources, including psychiatry, psychology, sociology, and community mental health. In this review, they are interpreted using a behavioral health perspective, supplemented with additional context from the relevant history, demographics, literary criticism, prior HT studies on related populations, and other related literature from both sides of the border. Taken together, the reviewed scholarship argues that the roots of socio-economic challenges and health disparities faced by IMA-US are not new, but rather echo experiences similar to those of their ancestors. Conversely, these works argue that in spite of the hardships, IMA-US exhibit several health advantages. For example, they are known for their ability to engage support from local and binational social networks (Hondagneu-Sotelo and Avila 1997; Silver 2014). Even though they have had limited access to health care, they frequently have secured alternative affordable wellness services that have been preserved in their communities for many generations (Hoskins and Padrón 2017; Zacharias 2006). More importantly, people of Mexican descent, on both sides of the border, have a history of coming together in social movements to advance their causes, which demonstrates that they are stronger together when fighting against social injustice. These findings are congruent with extensive sources that suggest that traditional health values, beliefs, and practices aided this population's survival through hundreds of years of colonial rule and subsequent political unrest (De la Peña 2006; Leon-Portilla 2011; Sahagún et al. 1970; Zacharias 2006). By elucidating their history, this interdisciplinary review provides a unifying perspective on mental health disparities for IMA-US, advancing our understanding of the systemic issues affecting their overall health.

\subsection{Population Demographics}

Individuals of Mexican ancestry in the United States (IMA-US) are this country's youngest, largest, and most diverse minority group. Their median age is 27 years, and they make up $11 \%$ of the U.S. population (Stepler and Brown 2016). Currently, one of every four children in this country identifies as Hispanic-Latino, and over $70 \%$ of these children trace their ancestry to México (Flores 2017; Murphey et al. 2014). Over twothirds of IMA-US were born in the United States, and a large majority of those born abroad have resided in this country for decades now (Gonzalez-Barrera and Lopez 2013; Stepler and Brown 2016). This pan-ethnic population includes the majority, IndigenousSpanish people (a.k.a. mestizo), ${ }^{1}$ various ethnic minorities, such as White, Black, Asian, Arab, Jewish, and Indigenous groups known as pueblos originarios ${ }^{2}$. The pueblos originarios represent the largest minority in México, and they also account for one of largest indigenous groups in the Americas (Eisenstadt 2011). The pueblos originarios include 60 communities with distinct languages and cultural traditions (INEGi XII 2001). Major indigenous groups include: Purepecha, Nahua, Mixtec (Ortiz 2014), Zapotec, Otomi (Fox

Mestizo refers to an individual of mixed race, especially one of Spanish and indigenous descent (De la Peña 2006).

2 Pueblos Originarios is a term used to identify human groups that descended from precolombian cultures of Mesoamérica that have preserved some of their social and cultural characteristics (De la Peña 2006). 
and Rivera-Salgado 2004), Maya (Aguilar et al. 2013), Tarahumara (Weaver 1992), and Huichol (Wiegand and Fikes 2004). Indigenous communities that share bonds across the U.S.-Mexican border include such tribes as the Tohono O'odham nation, the Kumeyaay People, the Yaqui, and the Kickapoo (Beltrán et al. 2021; Fernandez 2019). Roughly 30\% of the Mexican population claims indigenous heritage, with $10 \%$ identifying as non-mixed indigenous, and over 20\% claiming direct indigenous heritage (De la Peña 2006; INEGi XII 2001). However, recent research estimates that the majority of the Mexican population may be of Amerindian descent ${ }^{3}$ (Kumar et al. 2011). This research reports that the maternal ancestry of Mexican people is predominately Native American ${ }^{4}(85-90 \%)$, with a minority having European (5-7\%) or African (3-5\%) maternal ancestry. However, the paternal ancestry of the Mexican mestizo people is predominantly European (64.9\%), followed by Amerindian $(30.8 \%)$, and a small percentage (1.2\%) has been linked to Asian heritage (Kumar et al. 2011). Currently, the number of indigenous people in México has been estimated to be similar to the number of indigenous that populated the Mexican land before the Spanish invasion (INEGi XII 2001). Recently, the demographic distribution of the Mexican people in the United States has changed; there has been an increase in indigenous Mexican people migrating to the United States for the first time (Mines et al. 2010; Zúñiga et al. 2014). According to the census bureau, since the year 2000, there has been a three-fold increase in the population that identifies as both Indigenous and Hispanic, coming from countries in the Americas south of the U.S. (US Census Bureau 2000). Currently, the IndigenousHispanic group ${ }^{5}$ is the fourth largest Indigenous group in the United States (Fernandez 2019; Norris et al. 2012). For the purposes of this article, the term Indigenous Peoples of the Americas refers to the original inhabitants of North, Central, and South America, and their descendants (Barnhardt 2005; Brave Heart et al. 2011).

\subsection{IMA-US: Shared and Differential Social Experiences}

Although IMA-US present rich diversity at many levels, they represent a well-defined population. IMA-US share commonalities in their origin stories, social histories, and political struggles. For example, the majority of them share cultural traditions, socioeconomic challenges, and a colonial past, which spans over 400 years, encompassing several HTEs (De la Peña 2006; Kumar et al. 2011; Vasconcelos and González 1944). However, the impacts from HTEs have disproportionately affected indigenous people, with some consequences prevailing across generations (Zizumbo-Colunga and Martínez 2017). Historically, individuals with real or perceived indigenous heritage have faced harsher social conditions, such as lower opportunities for professional advancement, lower wages, inadequate access to housing, education, and health services (Navarrete 2005; SaldañaPortillo 2001; Zizumbo-Colunga and Martínez 2017). Furthermore, indigenous groups have also experienced marginalization and discrimination from their non-indigenous counterparts, on both sides of the border (Oehmichen 2007; Ramirez and Hammack 2014; Van Dijk 2019). The discussion of mental health outcomes and SUDs for IMA-US merits an a critical review of race-based disparities (Kendi 2019; Morris 2002; Viruell-Fuentes et al. 2012). A brief summary of their inter-racial dynamics is provided in Section 1.4.2. This summary facilitates understanding of the structural issues in the distribution of illness and wealth among IMA-US.

3 Amerindian descent: Individuals whose ancestors include people who lived in North, Central or South America before the Europeans arrived (Kumar et al. 2011)

4 Native American People: An individual of any of the first groups of people living in North, Central or South America. In general this terms has been used to identify members of one of these groups from the U.S, however, this terms is also used to identify members of one of these groups across the Americas Kumar et al. (2011).

5 Indigenous-Hispanic: Individuals living in the USA that trace their heritage to Native American groups from México, Central and South America and also identify as Hispanic (Fernandez 2019). 


\subsubsection{IMA-US: Within Group Differences}

Mexican Indigenous people experience significant social inequality in México, and when they migrate to the United States, these conditions often persist. They are often exposed to sexual, physical, and psychological violence during migration (Krieger et al. 2010; Pinedo et al. 2014; Valverde et al. 2015; Zúñiga et al. 2014). After arrival, they struggle with substandard employment conditions and access to adequate housing and healthcare services (Fernandez 2019; Norris et al. 2012). Research on the social determinants of health (Krieger et al. 2010) postulates that communities that experience prolonged exposure to adverse conditions, and limited access to health resources, are more likely to have an increased predisposition to behavioral health problems, such as psychological distress, SUDs, and other social impairments (Caballero-Hoyos et al. 2013; Castro et al. 2007). Therefore it is essential to trace the risks and protective factors moderating their health in order to develop targeted interventions. However, recognizing the health risks and resources of their broader communities/population is also essential for understanding the prevalence and distribution of health disparities within its subgroups (Albertani 1999; Barrera and Longoria 2018).

\subsubsection{Shared Experiences and the Broad Spectrum of Mestizaje}

Historically, discussions of Indigenous and African heritage have been repressed in public discourse regarding Mexican identity (Caminero-Santangelo 2004; De la Peña 2006). Similarly, the discussion of the strength of the genetic link between the mainstream population, mestizos, and the largest minority, pueblos originarios, has been limited and fraught with controversy (Antebi 2008; Cortázar 2015; Posadas 2012). Despite the historical (Leon-Portilla 2011), biological (Kumar et al. 2011) and cultural (Brandes 1998) evidence linking the large majority of Mexican people to the pueblos originarios, many mestizos do not recognize these links (Caminero-Santangelo 2004; Posadas 2012; Rizo 2003). This disconnection may be partly explained by the process of mestizaje, which by its nature makes it difficult to trace direct lineage. In México mestizaje refers to the inter-breeding between Indigenous, Spanish and African groups, a process that started during the colonial era and still continues today (De la Peña 2006; Vasconcelos and González 1944). This interbreeding resulted in a continuous spectrum of indigenous heritage that hinders any attempt to uniquely classify indigenous versus non indigenous groups (De la Peña 2006; Kumar et al. 2011; Leon-Portilla 2011; Navarrete 2004; Oehmichen 2007). Whereas a few minorities can trace their genealogical lineage, the largest majority assimilated into the Spanish-speaking culture cannot (De la Peña 2006; Leon-Portilla 2011; Sahagún et al. 1970).

Although indigenous groups have preserved and kept private many of their cultural elements, some traditional beliefs, attitudes, and practices have spilled over into the mainstream society through syncreticism. This refers to a cultural hybrid brought about by blending cultural practices from different social groups; practices that are later transformed to accommodate the evolving needs of the community (Broda 2003; De la Peña 2006). The engagement of the entire population in these hybrid traditions has been extensively studied (Brandes 1998; Broda 2003; Caminero-Santangelo 2004). These works indicate that even if it is difficult to ascertain the strength of the biological link between mestizos and the pueblos originarios, the non-indigenous population have always been actively involved with indigenous-based traditions (Brandes 1998; Oehmichen 2007). Currently, major traditions widely celebrated among Mexican people are based on precolonial thought, including Día de los muertos ${ }^{6}$, danza folklórica ${ }^{7}$, and traditional medicine ${ }^{8}$.

6 Día de los Muertos, or Day of the Dead, is a tradition that celebrates the lives of the deceased and honored their memories. This tradition is traced to precolonial times and is one of biggest celebrations in México (Brandes 1998).

7 Danza folklórica can be traced to ceremonial and social dances with roots in the precolonial era. Nowadays, every state has its unique dance that represents them. Sometimes a dance will depict an event, such as the conquest of México, an animal from the area, or another element of the local lifestyle (Mendoza 2001).

8 Traditional medicine, also known as medicina del campo and curanderismo, is a syncretic system of healing that involves a holistic approach to wellness (Hoskins and Padrón 2017). 


\subsection{Prior Research: A Decontextualized Perspective}

Prior mental health research has classified IMA-US under larger and highly heterogeneous categories, such as Hispanic (Alarcón et al. 2016; Fabrega 1990; Vega et al. 1985), Latino/x (Alegría and Woo 2009; Cabassa et al. 2017), minority (Cheung and Snowden 1990), and non-White (Leaf et al. 1987). Research that treats highly heterogeneous samples as a homogeneous unit of analysis runs the risk of overlooking triggers for disease as well as protective factors specific to the nations in these groupings (Guilamo-Ramos et al. 2020; Orozco-Hershey 2019). These works may also overlook differences in their histories of political violence, mass-trauma, marginalization, and health practices (Alvarez et al. 2004; Comas-Diaz 2001; García 2020; Gimenez 1989; Griner and Smith 2006; Guilamo-Ramos et al. 2020; Hunt et al. 2004). Moreover, these works have frequently used Anglocentric and Eurocentric theories to examine the health issues of these multi-ethnic categories (Gimenez 1989; Griner and Smith 2006; Guilamo-Ramos et al. 2020; Hunt et al. 2004).

Interventions that fail to account for population specific health vulnerabilities can lead to ineffective clinical assessment, treatment, and recovery regimes (García 2020; Griner and Smith 2006; Guilamo-Ramos et al. 2020; Hunt et al. 2004). Some limitations of such interventions have been attributed to the mismatch between the cultural norms informing this western-based research and the cultural norms of the target population (Battiste 2011; de Sousa Santos 2015; Smith 1999). This type of research has an etic orientation, in that it does not focus on situating the problems of minority groups in relation to their standing within their own countries, communities or the mainstream society (Battiste 2011; Griner and Smith 2006; Harding 1992; Hunt et al. 2004; Smith 1999). Etic oriented research tends to link cultural practices to external conditions that may not be relevant to target population (Battiste 2011; Harding 1992; Morris et al. 1999). In the attempt to generalize across groups with different historical backgrounds, such research may fail to be relevant to any individual group (Johnson 2006; Orozco-Hershey 2019).

This prior research has increased our understanding of the behavioral health problems relevant to IMA-US, by documenting the average prevalence of illness, risk, and protective factors across Hispanic-Latinx groups. However, these works have neglected to explain the origins of their healthcare disparities. Examining the etiology of health and social problems for IMA-US is especially relevant, because the unique historical relationship between México and the United States plays a role in their health disparities. For example, the geographical proximity between both countries enables transnational migration, labor, travel, and social exchanges between families, communities, organizations, and governments (HondagneuSotelo and Avila 1997; Massey and Denton 1993; Nevitte 2017; Silver 2014).

\section{Conceptual Framework: A Contextualized Perspective}

A new perspective is needed to advance our understanding of the socio-political and cultural factors moderating the health of IMA-US. Without an understanding of the interplay between these broader social issues and their health values, strengths, and vulnerabilities, it is difficult to ascertain the etiology of current health disparities. Thus, current treatments may not be addressing key sources of illness and distress (Griner and Smith 2006; Hunt et al. 2004). In general, aggregating groups with disparate social characteristics into a single unit of analysis may lead to overlooking differences between groups (GuilamoRamos et al. 2020; Gy 1992; Johnson 2006; Orozco-Hershey 2019). However, for the purpose of this review, the union of Indigenous and non-Indigenous people into a single category is difficult to avoid, because the majority of Mexican people have an unknown mixture of indigenous and Spanish heritage (Kumar et al. 2011; Vasconcelos 1993).

This article explores the shared experiences and values of Indigenous and nonIndigenous Mexican groups, as well as similarities in their patterns of behavioral health problems, adaptive responses, and cultural resources used to overcome hardships. Towards this goal, this paper examines their clinical predispositions and socio-environmental hazards in the context of their shared history, values, and legacy of colonization. This emic 
approach, also known as insider perspective, refers to an analytical stance that primarily uses the the target population's understanding of their own matters to examine the phenomena under study, which is often culturally and historically bound (Morris et al. 1999).

The proposed conceptual framework uses history as an axis to diagram socio-environmental hazards and historical traumatic events that have hampered the health trajectory of IMA-US, thus shaping their stress responses to deal with adverse social exposures. The historical trauma framework is used as a theoretical umbrella to encompass inter-related concepts. These concepts illustrate repercussions from HTEs on the current population, as well as the ways in which these narratives of trauma and survival were preserved and transmitted across generations. Next, these concepts are presented and then they are applied to the lived experiences of IMA-US. These include : HTEs (Walters and Simoni 2002), mechanisms of inter-generational transmission (Evans-Campbell 2008), colonial trauma response (Brave Heart et al. 2011; Evans-Campbell 2008), collective strength (Ortega-Williams et al. 2021), and the legacy of self resistance and determination (Evans-Campbell 2008; Ortega-Williams et al. 2021; Vargas-Hernández 2005).

\subsection{Historical Perspective}

For several decades now, a historical perspective has been integrated into behavioral health research (Kindig and Stoddart 2003; Szreter 2003). Historical trauma research focuses on examining impacts from HTEs on health outcomes for populations with histories of mass trauma (Brave Heart 1998; Duran 1995; Walters and Simoni 2002; Yehuda et al. 1998). This research first emerged to evaluate mental health outcomes of the descendants of holocaust survivors (Barocas and Barocas 1979; Phillips 1978; Yehuda et al. 1998, 2001). This work examined how impacts from this traumatic episode were transmitted intergenerationally to the survivor's descendants by means of biological, and cultural pathways Yehuda et al. $(1998,2001)$. According to this scholarship, experiences or memories of historical trauma are linked to a wide range of symptoms, including depression, self-destructive behavior, suicidal thoughts, anxiety, low self-esteem, anger, unresolved grief, and SUDs (Kirmayer et al. 2011; Prussing 2014; Yehuda et al. 1998, 2001).

The scholarship on historical trauma has been growing steadily for the past 20 years, primarily focusing on American Indian Alaskan Native (AIAN) groups (Brave Heart 1998; Walters and Simoni 2002). However, in the past decade, the historical trauma framework has been increasingly applied to other populations with histories of colonial trauma (Estrada 2009; Hanna 2017; Pihama et al. 2014; Pokhrel and Herzog 2014; WilliamsWashington and Mills 2018). As this research continues to expand, the debate about the applicability of the historical trauma framework has evolved. Frequent questions about this include (1) what exactly is being measured by survey instruments designed to assess the effect of HTEs (Mohatt et al. 2014; Whitbeck et al. 2004), (2) is the recollection of these traumatic experiences useful or detrimental to affected individuals and communities (Brave Heart et al. 2011), and (3) who is counted as indigenous (Anzaldúa et al. 2003; Fernandez 2019; Ramirez and Hammack 2014; Weaver 2001).

\subsection{Historical Trauma Framework}

In the United States, the historical trauma framework has been used primarily to explore the present-day socio-economic impacts and health outcomes for AIAN (Kirmayer et al. 2011; Prussing 2014). These works postulate that present-day stressors of AIAN interact with their history of colonial trauma, increasing vulnerability to mental health and SUDs in current populations (Brave Heart 1998). Historical trauma scholars argue that examining the historical events specific to each population under study is critical, because the interaction of their unique history with current stressors may result in differing health consequences for each group (Walters and Simoni 2002). Indigenous populations around the world reside in distinct local and political environments, thus they are inherently diverse, exhibiting a myriad of cultural, linguistic, and social differences. Therefore, the nature and mechanisms of transmission may be different for each group per their social 
histories and other contextual factors (Brave Heart et al. 2011; Kirmayer et al. 2011; Peña 2005; Pihama et al. 2014).

The extent of HT research ranges from building theory to testing instruments, as well as examining historical traumatic events, and its associated trauma responses (Kirmayer et al. 2011; Prussing 2014; Whitbeck et al. 2004). However, the extent of the presumed direct relationship between prior traumatic experiences of a population, and current social and health problems is undergoing empirical investigation (Evans-Campbell 2008; Gone 2013; Mohatt et al. 2014; Pokhrel and Herzog 2014; Sotero 2006; Walters et al. 2020; Whitbeck et al. 2004). Nevertheless, both supporters and critics of historical trauma research concur that Indigenous people have carried a complex burden from current and historical hardships, that has negatively affected their health. These scholars acknowledge that ongoing practices of systemic oppression and structural violence against Indigenous peoples can be traced to colonization policies, which persist today, albeit in different forms (Brave Heart 1998; Duran et al. 1998; Evans-Campbell 2008; Walters et al. 2011).

\subsubsection{Historical Trauma Concept, HTEs, and Adaptive Responses}

Broadly speaking, the concept of historical trauma, as applied to indigenous peoples from the Americas, refers to one or more acts of violence perpetrated against an entire group of people, or the majority of its members, due to their real or perceived identity, affiliation, or social status (Brave Heart 1998; Duran 1995). The purpose of these violent attacks is to annihilate, harm, subjugate or colonize the target population. The colonizers often destroy their cultural artifacts, systems of knowledge, economic infrastructures and seized their natural resources (Walters et al. 2020). After the invasion, many of the survivors were often enslaved, segregated, or forced into indentured servitude; however, some groups managed to escape by hiding, or retreating to the mountains or other geographical margins (Leon-Portilla 2011; Ramirez and Hammack 2014). Those ones that did not manage to escape were assimilated and acculturated into the beliefs and values of the ruling society (Okazaki et al. 2008; Thompson 1921; Tuck and Yang 2012).

The concept of historical trauma encompasses three main components: (1) historical traumatic events (HTEs), (2) mechanisms of transmission of these historical traumatic exposures and trauma narratives, as well as the impacts associated with these transmissions (Mohatt et al. 2014), and (3) both maladaptive and adaptive responses to historical and contemporary oppression (Walters et al. 2011; Walters and Simoni 2002). Whereas the majority of historical trauma research has focused on examining adverse outcomes from HTEs, fewer studies have explored the adaptive coping responses that emerged to deal with the social and health consequences from these traumatic episodes (Evans-Campbell 2008). This research has identified several areas that promise to reveal the vehicles used to transmit these adaptive responses, including the reconstruction of trauma narratives, collective strength, and enculturation: re-engagement with traditional cultural practices, health values, and Indigenous identity (Evans-Campbell 2008; Ortega-Williams et al. 2021; Walters and Simoni 2002; Whitbeck et al. 2004).

\subsubsection{Inter-Generational Transmission of Trauma}

The aftermath of historical trauma has been examined using a multi-level and intergenerational lens. This framework discusses (1) the ramifications of HTEs at the individual, family, and community level, (2) the vehicles that facilitated the transmission of these impacts across generations, and (3) behavioral responses to the trauma prompted by such exposures (Evans-Campbell 2008). At the individual level, this transmission has been linked to increased vulnerability to behavioral health problems, including post-traumatic stress disorder, survivor's guilt, anxiety, depression, obesity, and SUDs. At the familylevel, manifestations of historical trauma include communication impairments, stress around parenting, and attachment disorders in children. The impact at the communitylevel includes the abandonment of traditional cultural activities, loss of traditional rites of passage, and erasure of traditional values and health practices (Evans-Campbell 2008). 


\subsubsection{Colonial Trauma Response}

Reactions to HTEs have been discussed as historical trauma response (HTR), also known as colonial trauma response (CTR). This concept refers to emotions and behaviors that stem from direct or indirect exposure to traumatic events (Evans-Campbell 2008). In general, historical trauma research indicates that even though such events took place in the distant past, their consequences continue to affect the survivor's descendants (Mohatt et al. 2014). This research suggests that descendants of survivors from historical trauma may experience cognitive dissonance from discrepancies or disconnections between current social conditions, historical facts known to them, and the stress reactions and coping responses exhibited by their parents and grandparents, especially when they are under duress (Prussing 2014). Often the survival skills that emerged at the onset of HTEs do not match the coping skills needed to deal with present conditions. From the perspective of the descendants of HT survivors, this mismatch may be experienced as post-colonial stress/suffering in their communities (Evans-Campbell 2008; White 1998).

\subsubsection{Resistance through Collective Strength}

The concept of collective strength highlights the social cohesion and power that can be harnessed when communities with histories of colonization work together towards mass healing (Ortega-Williams et al. 2021). This concept is derived from the integration of the historical trauma framework (Brave Heart 1998; Walters et al. 2020), and the Post-Traumatic Growth Framework (PTG) (Tedeschi and Calhoun 1996). This integrated model, the Historical Trauma and Post Traumatic Growth Framework (HT-PTG), promotes social change through: an understanding the political climate of the social context in which the traumatic episode took place. Towards this goal, HT-PTG reviews the relationships among individuals and groups involved in the traumatic experience and examines the dynamics brought about by the participant's roles (i.e., witnesses, victims, leaders, and perpetrators). This model outlines specific mechanisms to promote recovery from $\mathrm{HT}$ at the community-level. The mechanisms are (1) collective strength, (2) collective spiritual change, (3) relating to ancestors and culture, (4) new possibilities for collective destiny, and (5) appreciation for our lives. HT-PTG also proposes identifying the values that motivate people to mobilize for change (Ortega-Williams et al. 2021).

\subsection{Application of Conceptual Framework to the Lived Experiences of IMA-US}

\subsubsection{Understanding the Social Context: Health Vulnerabilities}

People of Mexican ancestry have experienced harsh social conditions relative to Hispanic and Latinx groups (Fernandez 2019; Intrator et al. 2016; Vigil and Lopez 2004). In general, IMA-US have been economically disadvantaged, with an estimated poverty rate of 24.9\% (González de Alba 2010; Semega et al. 2017), a figure that is similar to the AIAN population, estimated at 25.4\% (Fernandez 2019; Semega et al. 2017). Even though IMA-US have one of the highest levels of participation in the workforce, their participation has been undervalued (Borjas and Katz 2007). Whereas many IMA-US may occupy jobs in settings where they had been previously underrepresented, fewer have achieved higher level positions within their companies (Borjas and Katz 2007; Glenn and Tam 2004). The educational level for IMA-US has lagged behind almost any other group. For example, they have the lowest college attainment rate: approximately only $12 \%$ of them ages 25 and older obtained at least a bachelor's degree, a figure that is lower than that of other Hispanic groups (16\%) (Noe-Bustamante et al. 2019).

\subsubsection{Understanding Political Context: Social Vulnerabilities}

These social hardships are not surprising, given that the series of major traumatic events in the lifetime of this population is extensive. Mexican people have only been free from major warfare for less than 100 out of the past 500 years (see Figure 1), not counting the many instances of internal rebellion, resistance, political oppression, and mass violence (Bonfil Batalla 2020; De la Peña 2006; Vasconcelos and González 1944). In the 
clinical setting, individuals with an extensive history of trauma and adversity would be considered to have higher predisposition for behavioral health problems (Cohen et al. 2012). Similarly, an extensive history of traumatic episodes in a population would lead to higher predispositions for disease among its members (Kindig and Stoddart 2003). However, the impacts from HTEs would differ according to the specific histories of trauma in each subgroup of the population, and their recovery would be conditioned on the quantity and quality of structural supports available for their treatment, as well as the social and institutional climate in which the recovery takes place (Estrada 2009; Talebreza-May 2015; Van Dijk 2019).

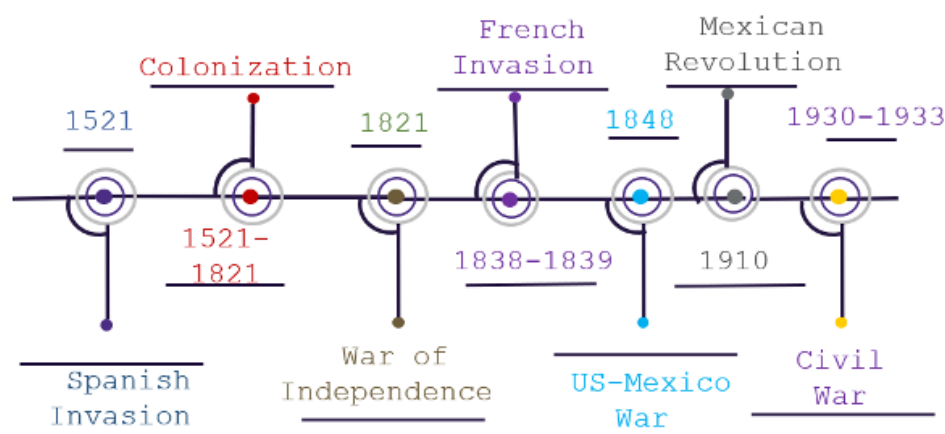

Figure 1. Timeline of Historical Trauma Events.

\subsubsection{Health Advantages: Community Resources and Collective Strength}

Despite the disproportionate exposures to social adversity, the prevalence rates of mental illness and SUDs for IMA-US have been estimated to be similar to those of the general population (Alegría et al. 2007; Borrell and Lancet 2012). This is counter-intuitive because one would expect that higher exposure to adversity would lead to a higher prevalence of behavioral health problems (Krieger et al. 2010). The sources reviewed here echo findings from preventive research that suggests that exposure to adversity may be attenuated in affected communities due to cultural and socio-environmental buffers (Henry and Stephens 2013; Nurius and Hoy-Ellis 2013). In this paper, these buffers are described as health advantages: the social and environmental resources optimized by communities to maintain wellness and cope with social hardships.

Historically, both Indigenous and non-Indigenous Mexican groups, from both sides of the border, have shared experiences of structural oppression. However, despite differences in the severity of these hardships for each group, and in spite of their social tensions, they have often united against systemic oppression, and their social movements have changed the political landscape of their times. Some bi-national examples of these achievements include the War of Independence (Vasconcelos and González 1944), the Mexican Revolution (Bonfil Batalla 2020), the Movimiento Indigenista/Indigenist Movement (Bueno 2015), the Movimiento Zapatista/The Zapatist Movement (Vargas-Hernández 2005), the Movimiento Estudiantil de 1968/The Student's Movement of 1968 (Revueltas et al. 1978), the Chicano Movement (Muñoz 2007), the Farmworkers Movement (Ferriss and Sandoval 1997; Zentella 2004), and the DACA movement (Mena Robles and Gomberg-Muñoz 2016).

\subsubsection{Mexican Values and Philosophies}

The values and philosophical stances embraced by IMA-US are embodied in political slogans, such as la unión hace la fuerza/the union makes the force (Cohn and Delgado 2005), si se puede/yes, we can (Cohen-Chen and Van Zomeren 2018), el pueblo unido jamás será vencido/the people united will never be defeated (Vargas-Hernández 2005), and Tierra, Libertad y Ley/Land, Freedom and Law (Huirimilla 2007). These values have been expressed in these transnational communities generation after generation, and can be observed in social discourses and popular culture across both sides of the border Zentella $(2004,2009,2014)$. This history of 
social movements makes evident that throughout these difficult chapters, multiple groups, including Indigenous, Indigenous-Spanish, and other minorities, have come together to seek freedom from structural oppression (De la Peña 2006; Vasconcelos and González 1944). This may be because in addition to sharing social hardships, they also share a legacy of resistance. Time and time again, Mexican people have shown that they are stronger together when they join forces towards the same goal. (Garduño 2004; Oliva de Coll 1976; Soriano Hernández 1994).

\subsubsection{Mobilization for Social Change: Legacy of Resistance and Self-Determination}

Recent scholarship addressing post-traumatic stress of populations that were previously colonized, or targeted due to their ethnic affiliation, has introduced a paradigm shift in clinical oriented research, this includes using a collective approach to healing from historical traumatic experiences (Ortega-Williams et al. 2021; Tedeschi and Calhoun 1996). This scholarship explains that historically oppressed groups have used inter-group alliances and collective power to survive harsh social conditions (Chávez 2015; Ortega-Williams et al. 2021; Vargas-Hernández 2005). Extensive bodies of literature have shown that when communities face structural violence, individual efforts are not sufficient to counter systemic issues (Ferriss and Sandoval 1997; Frankl 2011; Johnson 2019; Rickford 2016; VargasHernández 2005). The HT-PTG framework advocates promoting mass healing from HTEs by developing interventions that transfer the burden of healing from the individual to the collective (Ortega-Williams et al. 2021). This framework indicates that collective memories and narratives from HTEs hold the key to discovery of the survival strategies; this knowledge is a cultural legacy of resistance that has been passed down across generations (Walters et al. 2020). Interventions based on these principles are more likely to be adopted and sustained by all Mexican communities, because of their congruence with familiar wellness traditions (Damschroder et al. 2009; Kirmayer et al. 2012; Proctor et al. 2011).

\subsubsection{Historical Trauma Framework}

Despite the striking similarities in the history of colonization between AIAN and IMA-US, only a few studies have used the historical trauma framework in mental health conceptualizations for this population (Estrada 2009). This is perhaps because the ramifications of the invasion and colonization of México have not been widely recognized as historical trauma (De la Peña 2006; Posadas 2012). However, according to the broader literature addressing HT for related populations (i.e., AIAN), both Mexican Indigenous and non Indigenous groups bear the scars of historical and contemporary oppression (Brave Heart et al. 2011; Evans-Campbell 2008). However, it is clear that this oppressive history has resulted in significantly worse social inequalities for Indigenous people (Zizumbo-Colunga and Martínez 2017). This social disadvantage results in greater disparities across all sectors, including housing, education, workforce, and health care services. Even though many HTEs happened in the past, political instability and violence against indigenous people persist today on both sides of the border (Fernandez 2019; Mohatt et al. 2014; Vargas-Hernández 2005; Zúñiga et al. 2014). In México, their struggle for freedom, land, and law continues (Huirimilla 2007). Currently, their human rights movement features a more basic demand, the right to be visible/Estamos Vivos (Martínez Coria and Haro Encinas 2015; Morales 1989). In the United States, the social inequalities for migrant workers have been extensively recorded, the large majority of these workers are indigenous people from south of the United States (Fernandez 2019; Norris et al. 2012; Zúñiga et al. 2014).

Estrada (2009) was the first to explicitly use HTT to examine behavioral health outcomes of IMA-US. In this paper, an extensive historical literature is presented to document prior and current oppression faced by IMA-US. This work argues that inequality and marginalization contribute to adverse social and health outcomes, leading to current health disparities (Cacari-Stone and Avila 2012; Krieger et al. 2010; Suleman et al. 2018; Varcoe et al. 2014). Estrada (2009) traces the onset of institutional racism toward IMA-US to the 
war between México and the United States (1848). Estrada (2009) cites sources that illustrate the mistreatment of IMA-US by social and health agencies, which was expressed in the forms of race-based profiling, housing discrimination, educational neglect, inadequate health treatments. Related research supports findings indicating that, when conditions of inequality and injustice are found in the service delivery polices of welfare institutions, such services become iatrogenic, worsening health outcomes for the affected populations and compromising their trust in welfare organizations (Battiste 2011; Cacari-Stone and Avila 2012; Suleman et al. 2018).

\subsection{Colonial Trauma Responses}

Behavioral health scholars focused on American Indigenous people argue that the erasure of indigenous heritage is the legacy of colonization, a legacy that is embedded in the fabric of society, including education and other public venues (Evans-Campbell 2008; Walters et al. 2011). The denial of traumatic experiences represents a normative reaction that follows after such exposures (Cohen et al. 2012). During the colonial era, embracing indigenous identity was perceived as a threat to the physical and psychological integrity of the survivors (Anzaldúa et al. 2003; Talebreza-May 2015; Zentella 2004, 2009, 2014). Therefore denying indigenous heritage by adopting the colonial identity was a way to ensure survival, and secure greater social mobility, a survival strategy that was passed down across generations (Caminero-Santangelo 2004; De la Peña 2002; Van Dijk 2019). The fact that the slogan of one contemporary social movement of the indigenous people of México is "Estamos Vivos/We are Alive" points to the public denial of their existence.

For IMA-US, this denial has been transmitted across generations through many social venues, including the public school system, which until recently was minimizing the existence of indigenous people (De la Peña 2002). The detachment of the general population from their indigenous roots can be traced to the survival responses crafted during the colonial era, including assimilation, acculturation, and concealment of indigenous identity (Anzaldúa et al. 2003; De la Peña 2006; Oehmichen 2007; Talebreza-May 2015; Zentella 2004, $2009,2014)$. In indigenous communities, this legacy of colonization played out somewhat differently. Those that were able to evade forced assimilation by self-segregating exhibit resistance to cultural displacement by maintaining their languages, culture, and traditional health systems, despite ongoing persecution, discrimination, and political violence (De la Peña 2006; Hoskins and Padrón 2017; Huirimilla 2007).

\section{Limitations in Using Historical Trauma Framework on IMA-US}

One complexity of historical trauma research is the difficulty of establishing direct links between past historical trauma events and current clinical issues in the affected populations (Gone 2013; Kirmayer et al. 2011; Mohatt et al. 2014). However, from a theoretical standpoint the tenets of historical trauma are comparable to the those of wellestablished theories of interpersonal trauma (Cohen et al. 2012), which postulate that contemporary exposures to trauma can activate memories of prior traumatic experiences, leading to adverse symptomatology in those with trauma histories (Brave Heart et al. 2011; Cohen et al. 2012; Walters and Simoni 2002; Yehuda et al. 1998).

Another concern stems from the identification with Indigenous identity. Whereas the majority of people of Mexican descent have indigenous heritage (Kumar et al. 2011), a few do not have this heritage, and many that do have it may be unaware of this connection or may deny it (Anzaldúa et al. 2003; Caminero-Santangelo 2004; De la Peña 2006). Moreover, scholars in this field indicate that the application of historical trauma to groups with mestizo origins is inappropriate because these groups have privileged the Spanish language and culture over the indigenous languages and identities, thereby relinquished their indigeneity (Anzaldúa et al. 2003; Estrada 2009). However, this stance has been contested due to the fact that many mestizos were forcibly assimilated by colonizers, or were born in assimilated households and communities (Talebreza-May 2015; Zentella 2014). Moreover, many mestizos were also forced to carry out marginalization acts against their indigenous 
counterparts by the colonizers (De la Peña 2006; Leon-Portilla 2011; Oehmichen 2007; Vasconcelos and González 1944). These controversies pose several obstacles to advancing HT research for IMA-US.

\section{Methods}

\subsection{Philosophical Framework}

An interdisciplinary framework was crafted to inform the selection of this topic, the research methods, and analytic tools (Clarke et al. 2015; Drisko 1997; Mingers 2001; Onwuegbuzie et al. 2012; Rundle 2014; Van Dijk 2006). This interdisciplinary framework is grounded in history (Bonfil Batalla 2020; De la Peña 2006; Leon-Portilla 2011; Sahagún et al. 1970; Vasconcelos and González 1944). It integrates the work of several indigenous scholars (Battiste 2011; Beltrán and Begun 2014; de Sousa Santos 2015; Duran 1995; Evans-Campbell 2008; Fernandez 2019; Okazaki et al. 2008; Ortega-Williams et al. 2021; Smith 1999; Walters and Simoni 2002; Weaver 2001), and feminist thinkers (Anzaldúa et al. 2003; Ginorio and Huston 2001; Harding 2004; Mohanty 1988; Sandoval 2009). Making explicit the theoretical foundation is especially important when examining the lived experience of individuals or groups. Lived experiences are often discussed within a social constructivist paradigm, which assumes that perception of reality is not fixed, but rather is constructed within changing social and historic contexts (Creswell and Creswell 2017). Therefore, outlining the philosophical foundation, as done in this paper, enhances transparency and rigor of this review (Honebein 1996).

\subsubsection{Interdisciplinary Approach}

Fields of study that are well-established can rely on dominant theoretical frameworks, methods, and keywords (Chambers et al. 2018), but emerging fields require a tailored methodological and conceptual approach (Rundle 2014). The qualitative protocols integrated here yielded a unifying theoretical and methodological foundation to examine this collection of articles within a broader yet more inclusive perspective. As a result, sources of knowledge located at the margins of mainstream behavioral health discourses were incorporated into this paper, advancing the development of indigenous knowledge (Smith 1999). The methodological approach features a pluralistic design that merges complementary qualitative protocols to ensure (1) a comprehensive identification of sources (Levac et al. 2010), (2) tools for translating interdisciplinary fields (Miller 2001; Miller and Forrest 2001; Mingers 2001) and (3) analytic procedures for optimal integration and interpretation of findings (Maguire and Delahunt 2017; Onwuegbuzie et al. 2012; Van Dijk 1983, 2004; White 1998).

\subsubsection{Reflexivity Statement}

One way to operationalize the philosophical framework is by engaging in a reflexive process, which involves monitoring the researcher's relationships with the data, troubleshooting the methodological process, and optimizing tools for searching sources, analyzing and interpreting findings (Coffey and Atkinson 1996; Patnaik 2013; Watt 2007). In this paper, the writer, a practitioner-researcher, emphasizes the history of major traumatic events in the lifetime of the population, because the public health agenda calls for an emic perspective to develop targeted interventions for populations with histories of colonial trauma (Evans-Campbell 2008; Kindig and Stoddart 2003; Morris et al. 1999; Proctor et al. 2011; Smith 1999). Trauma-informed models posit that recovery from trauma involves not only the reconstruction of trauma exposures, but also the review of strengths and resources associated with such exposure (Cohen et al. 2012; White 1998). This writer has clinical expertise in trauma-informed and narrative therapy models, she also holds a bachelors degree in Language and Literature of Hispanic America, and shares the ethnic affiliation with the population of study, facilitating an emic/insider perspective with regards to historical, clinical, and cultural issues discussed in this paper. 


\subsection{Scoping Review Methodological Framework}

The scoping review methodological framework was selected for this research project because its purpose is to comprehensively map the literature on a broad or interdisciplinary topic (Peters et al. 2015). This feature facilitates identifying sources of knowledge situated at the margins of dominant research fields (Chambers et al. 2018; de Sousa Santos 2015; Smith 1999). Because this type of review prioritizes identifying all relevant sources, some have argued that the protocols for analysis are limited (Peters et al. 2015). This paper makes up for this limitation by integrating an interdisciplinary approach to the analytic process (Onwuegbuzie et al. 2012; Rundle 2014). Thematic analysis (Maguire and Delahunt 2017) is suitable in this context because it offers flexible protocols that can be incorporated into the scoping review methodological framework. Moreover, thematic analysis can be fitted with any conceptual framework to optimize the search over relevant topics (Clarke et al. 2015; Maguire and Delahunt 2017). In this paper, the preliminary coding scheme was informed by the goals of the review and the concepts outlined in the conceptual framework Section 2.

\section{Contextual Literature: Complementary Narrative Reviews}

Since the collection of work reviewed here is sparse, the scoping review was bolstered with brief narrative reviews (Ferrari 2015; Green et al. 2006) to providede a more robust context for the analysis (Onwuegbuzie et al. 2012; Van Dijk 1983). These complementary narrative reviews informed the problem statement, historical background and the theoretical framework (Onwuegbuzie et al. 2012). The narrative review method (Green et al. 2006) is appropriate for a comprehensive review of a wide range of literature. This type of review allows the inclusion of studies from multiple disciplines that may include research at different stages of development, including highly relevant grey sources (Green et al. 2006). The inclusion of this multi-disciplinary research was necessary because the analysis of the selected literature can be better understood within the sociopolitical context of the dominant research Van Dijk $(1983,2004)$. Gaps in the description of historical events (i.e., the Spanish invasion, colonization, the Gold Rush of California, and US-México War) were addressed by including historical research on this topic (Bonfil Batalla 2020; Chan 2000; Leon-Portilla 2011; Matamoro 1990; Peña 2005; Rojas 2007).

The conceptual framework was informed by prior research on populations with similar social histories (Brave Heart 1998; Evans-Campbell 2008; Kirmayer et al. 2011; Mohatt et al. 2014; Ortega-Williams et al. 2021; Prussing 2014; Walters and Simoni 2002; Yehuda et al. 1998). Selected articles were used to inform the prevalence and distribution of mental health and substance use patterns among IMA-US (Alegría et al. 2007; Alvarez et al. 2004; Catalano et al. 2000; Grant et al. 2004; Kessler et al. 2006; Mines et al. 2010; Zúñiga et al. 2014).

The integration of the narrative reviews was guided by qualitative techniques (Onwuegbuzie et al. 2012). These techniques provide guidance to integrate and contrast one or more components from one body of literature or source against the corresponding components from other sources. For example, in this article, I contrasted the epistemological stances of two different branches of research examining mental and substance abuse disorders relevant to the Mexican population (see Sections 1.5 and 2). The selected qualitative techniques also facilitated the reconstruction of a historical time-line, which was used to organize the partial stories narrated by each article obtained with the scoping method. This narrative approach was particularly important for this review because it facilitated the reconstruction of origin stories from the subject's point of view (IMA-US), reinforcing the original identities lost during the invasion and colonization (Evans-Campbell 2008; Morris et al. 1999; White 1998). By including these alternative stories we can make sense of factors that could appear to be unrelated events in the health trajectory of this population Van Dijk $(2004,2004)$. 


\subsection{Thematic Analysis}

Thematic analysis is often used to analyze qualitative data, such as interview transcripts or a collection of interrelated sources. The main purpose of this approach is to identify common themes, topics, ideas, and patterns of meaning across the sources (Clarke et al. 2015; Maguire and Delahunt 2017). There are various approaches to conducting thematic analysis. One common approach follows a six-step process: (1) familiarization with materials, (2) preliminary coding, (3) generating themes, (4) reviewing and refining themes, (5) defining and naming themes, and (6) writing the results (Clarke et al. 2015; Maguire and Delahunt 2017).

\subsection{Discourse Analysis}

Principles of discourse analysis were used to refined the search strategy, coding, and interpretation processes (Van Dijk 1983). The purpose of discourse analysis is to examine the content of the sources not only within a field, but between fields; it seeks to identify meaning in the context of the different disciplines, and the socio-political context in which these sources emerged Van Dijk $(2004,2006)$. This step was necessary because the reviewed articles come from several fields, presenting high variability in keywords, concepts, theoretical, and methodological approaches. Discourse analysis aided the classification of terms across these interdisciplinary fields into the behavioral health nomenclature (see Table 1).

Table 1. Selected sources. Population, Topic of Interest, and Context under which the topic of interest is examined.

\begin{tabular}{rlll}
\hline Sources & IMA-US & Topic of Interest & Context: HTEs or Framework \\
\hline * Anzaldúa et al. (2003) & Yes & Anxiety, depression & Invasion of the Americas \\
Brave Heart et al. (2011) & Yes & Behavioral health & Invasion of the Americas \\
Carvajal and Young (2009) & Yes & Behavioral health & Historical Trauma \\
Cromer et al. (2018) & Yes & Behavioral health & Intergenerational Transmission of Trauma \\
Estrada (2009) & Yes & Behavioral health & Indigenous Stress and Coping Model \\
$* * *$ Grayshield et al. (2015) & Yes & Grief & Colonization of the Americas \\
Hanna et al. (2017) & Yes & Behavioral health & Historical Trauma \\
Mohatt et al. (2014) & Yes & Behavioral health & Historical Trauma \\
Perez and Arnold-Berkovits (2018) & Yes & Ambiguous grief & Ambiguous loss of Homeland \\
Ramirez and Hammack (2014) & Yes & Depression/Grief & California Gold Rush \\
Stevens et al. (2015) & Yes & Behavioral health & Intergenerational Transmission of Trauma \\
Talebreza-May (2015) & Yes & Aggression, SUDs & Treaty of Guadalupe \\
Whitbeck et al. (2004) & Yes & Behavioral health & Historical Loss \\
$* *$ Zentella (2004) & Yes & Land-based disorders & US-México War \\
Zentella (2009) & Yes & Land-based disorders & Invasion of the Americas \\
Zentella (2014) & Yes & Unresolved grief & Colonization \\
\hline
\end{tabular}

Inclusion/exclusion criteria for these peer-reviewed sources included: (1) publication time (2008-2018), (2) inclusion of IMA-US, (3) utilization of historical perspective. Exceptions to the inclusion criteria were adjusted for the following sources: criteria (1) was waived for $\left(^{*}\right)$ because this seminal paper was highly cited across the selected sources, this criteria was also waived for item $\left({ }^{* *}\right)$ because it belongs to a trilogy of articles by one of the selected authors. The source $\left(^{* * *}\right)$ does not explicitly mentions inclusion of IMA-US in the sample, however, one research participant (author) makes a positionality statement regarding her Mexican background.

\subsection{The PICo Framework}

Another methodological adaptation was added to achieve the goal of the review, the inclusion of the PICo framework for qualitative studies. PICo stands for population, topic of interest, and context under which the topic is being examined (Miller 2001; Miller and Forrest 2001). The initial searches failed to produce a consistent set of keywords that yielded all the relevant studies examining the behavioral health of IMA-US, under a historical perspective. This failure to allocate these sources was in part because studies relevant to IMA-US used a variety of terminology to refer to this and closely related populations (see Section 4). The PICo framework was used to optimize the search strategy and the inclusion/exclusion criteria. This framework is widely use in clinical research to comprehensively capture sources with a shared population, topic of interest, and context 
under which the topic is examined. This form was developed by Murdoch University (2009), see Appendix A Figure A1. For the purposes of this paper, a historical perspective is defined as including the description of HTEs or utilization of a historical trauma or related framework (see Table 2).

Table 2. HTEs and Concepts.

\begin{tabular}{rll}
\hline Source & HTEs & Theoretical Framework/Concept \\
\hline Anzaldúa et al. (2003) & Invasion of the Americas & Split-Mind and Unresolved grief \\
Brave Heart et al. (2011) & Invasion of the Americas & Historical Trauma \\
Carvajal and Young (2009) & Colonization of the Americas & Historical Trauma and Multilevel Framework \\
Cromer et al. (2018) & Invasion of the Americas & Historical Trauma and Institutional Betrayal \\
Estrada (2009) & U.S. -México War & Indigenous Stress and Coping Model \\
Grayshield et al. (2015) & Colonization of the Americas & Historical Trauma \\
Hanna et al. (2017) & Colonization of the Americas & Historical Trauma \\
Mohatt et al. (2014) & Invasion of the Americas & Historical Trauma \\
Perez and Arnold-Berkovits (2018) & Forced Relocation & Ambiguous loss of Homeland \\
Ramirez and Hammack (2014) & California Gold Rush & Historical Trauma and Survivance \\
Stevens et al. (2015) & Colonization & Intergenerational Transmission of Trauma \\
Talebreza-May (2015) & U.S.-México War & Colonialism and Cultural Trauma \\
Whitbeck et al. (2004) & Invasion of the Americas & Historical Loss \\
Zentella (2004) & US-México War & Land-based disorders \\
Zentella (2009) & Invasion of the Americas & Land-based disorders \\
Zentella (2014) & Colonization & Unresolved grief \\
\hline & &
\end{tabular}

\subsection{Search Strategy}

The search process started with a set of broad keywords, concepts, and phrases, which were explored to expand or restrict subsequent searches (Arksey and O'Malley 2005). The initial set of keywords included the following: ("Mexican" OR "Mexican American" OR "Mexican Indigenous" OR "Mexican American Indian,") AND ("mental health" OR "substance abuse,") AND "historical trauma." The searches were conducted in six major databases: Academic Search Complete, Social Work Abstracts, Psych INFO, Web of Science, SCOPUS, and Google Scholar. Initially only three sources were identified, however, through a recursive search process, conducted from January through October 2018, over 100 candidate sources were identified, ultimately leading to sixteen selected sources. These sources includes a variety of methodologies and theoretical frameworks.

\subsection{Inclusion/Exclusion Criteria}

The selection of sources followed a three-stage screening protocol. First, a screening was conducted to identify the keywords or their semantic equivalents in (a) the title of the study, then, (b) in the abstract, and finally (c) in the entire body of the paper. The references were also screened manually to identify relevant sources (Levac et al. 2010). The eligibility criteria were defined as follows:

1. Population. Eligible sources included or mentioned Mexican and/or Mexican Indigenous in the sample population, or a discussion about this population was included in the body of the paper.

2. Topic of Study. Eligible sources discussed behavioral health issues (i.e., depression, anxiety, substance use disorders, other mood and adjustment disorders).

3. Context. Eligible sources had to discuss the behavioral health of IMA-US in the context of HTEs or a historical trauma and/or related frameworks (as seen in Table 2).

4. Peer-Reviewed these selected studies were peer-reviewed, written in English and published from 2008 through 2018.

5. Exceptions to inclusion criteria of publication period were adjusted for some sources because the work was either a seminal paper that was highly cited across the selected sources (Anzaldúa et al. 2003), or because other studies in the same series of papers by an author were included in the selected sources (Zentella 2004). The criteria for 
inclusion of IMA-US was slightly modified for a few studies, because even though these sources did not explicitly mention inclusion of IMA-US in the sample, their presence was implied in the body of the paper (Brave Heart et al. 2011; Cromer et al. 2018; Grayshield et al. 2015; Mohatt et al. 2014; Whitbeck et al. 2004); for example, these studies indicated that the geographical location in which the study took place is highly populated by IMA-US, such studies mentioned the inclusion of unaffiliated indigenous tribes, which are often Mexican communities. In one study, a co-author identified as an IMA-US, and included a positionality statement regarding her heritage (Grayshield et al. 2015) as motivation for the study (see bottom of Table 1).

\section{Results}

\subsection{Overview of Selected Sources}

These search process resulted in a set of 16 qualitative and quantitative peer-reviewed articles published in English from 1998 through 2018. These works define their population of study under a variety of unifying traits, including Mexican ancestry as well as broader categories (i.e., Hispanic, Latinx, American Indigenous). These sources explicitly or implicitly discussed behavioral outcomes for (1) the target population (IMA-US), (2) presented principles and components of HTT, or related frameworks, and (3) described one or more HTEs (see Table 3). These works suggest that current social ills and health inequities are not discrete and isolated events, but they rather represent the cumulative effects of a continuous spectrum of adversity (Evans-Campbell 2008).

Table 3. Descriptions of populations that intersect IMA-US.

Population
La Raza
Indigenous People of the Americas

North-American Indians

AIAN

Mexican

\section{Description}

This term coined by Vasconcelos (1993) denotes an overarching and collective cultural orientation that describes the relationship between the indigenous ancestors of Mexico and their descendants living in both Mexico and the United States (Estrada 2009; Talebreza-May 2015; Zentella 2004)

Indigenous peoples from North, South and Central America and their descendants (Brave Heart et al. 2011).

People from North America, including Canada, México and the United States (Nevitte 2017).

Native American people from the United States, it can include affiliated and unaffiliated tribes (Farley and Haaga 2005), often indigenous groups from México are included as non-affilaited tribes (Fernandez 2019).

People born in México, or holding Mexican nationality through naturalization or parental links. It includes White, Black, Arab, Jewish, indigenous, Indigenous-Spanish (mixed/mestizo), and non-indigenous groups (INEGi XII 2001).

\begin{tabular}{ll}
\hline MAI & Mexican American Indian living in the United States (Fernandez 2019; Humes et al. 2011). \\
\hline Mexican-American & People of Mexican ancestry born in the United States (Estrada 2009). \\
\hline & "Is the assertion of an Indian identity, one made problematic by the simultaneous \\
Chicano/x & acknowledgement of our Spanish, African, etc, heritages, our mestizaje."(Anzaldúa et al. \\
& 2003).
\end{tabular}

Hispanic People from Spain or from Spanish-speaking countries in Latin America, this term excludes people from Brazil, where Portuguese is the official language (Flores 2017).

Latino/a/x People from Latin America regardless of their official language, this term includes people from Brazil but excludes individuals from Spain (Flores 2017).

A group that has different national or cultural traditions from the main population. Four major racial and ethnic groups include: African Americans, American Indians and Alaska Natives, Asians and Pacific Islanders, and Hispanics (Cheung and Snowden 1990; US Census Bureau 2000). 


\subsection{Theoretical Characteristics}

The use of conceptual models varied; the majority of articles explicitly link historical trauma to IMA-US (Carvajal and Young 2009; Estrada 2009; Stevens et al. 2015), but other sources focused on related models that can be traced to the HT (see Figure 2). For example, the Indigenist Stress and Coping Model (Estrada 2009; Stevens et al. 2015) and the multi-level transmission for exploring impacts of historical trauma on individuals, families, and communities (Hanna et al. 2017; Stevens et al. 2015). Some of these models advanced our understanding of the mechanisms of transmission and impact from exposure to HTEs, with the concepts of historical loss (Whitbeck et al. 2004), survivance (Cromer et al. 2018; Grayshield et al. 2015; Ramirez and Hammack 2014), and land-based frameworks (Talebreza-May 2015; Zentella 2004, 2009, 2014). The concept of an ambiguous homeland (Perez and Arnold-Berkovits 2018) was the focus of one study, but this theme was evoked in other studies that discussed immigration issues, border movement, and land displacement (Anzaldúa et al. 2003; Hanna 2017; Stevens et al. 2015). Impacts from HTEs were also indirectly discussed with concepts of acculturation and minority stress (Carvajal and Young 2009; Perez and Arnold-Berkovits 2018; Stevens et al. 2015).

Some sources present innovative conceptual maps that expanded on different aspects of historical trauma, these introduced concepts remarking the impact from HTEs on individual and collective identities. For example, the concept of split-mind, a term that expresses psychological symptoms from mestizaje (Anzaldúa et al. 2003), similar to those of children born from sexual assault (Van Ee and Kleber 2013). Related concepts described identitydisorder syndromes included el desmadre/the chaos or the demothering, this concept refers to the disruption caused by the Spanish invaders, it represents the sense of loss that a child experiences when forcibly removed from the mother Zentella $(2009,2014)$. Concepts refer to as hidden identity and Hispanic Identity as a Jail Identity represent the need to hide the indigenous identity in order to protect it from colonizers, and to ensure survival during the colonial period (Talebreza-May 2015; Zentella 2004, 2009, 2014). The discussion of specific intergenerational trauma transmission and responses included, SUDs, mental health problems. The main venues for transmission included popular culture and oral tradition (Carvajal and Young 2009; Hanna et al. 2017; Stevens et al. 2015). Concepts related to the history of broken land treaties and current health disparities included institutional betrayal and institutional mistrust (Hanna et al. 2017; Ramirez and Hammack 2014; Talebreza-May 2015; Zentella 2004). Concepts of Indigenous methodologies, feminist, and critical race theory were included in several sources (Cromer et al. 2018; Grayshield et al. 2015).

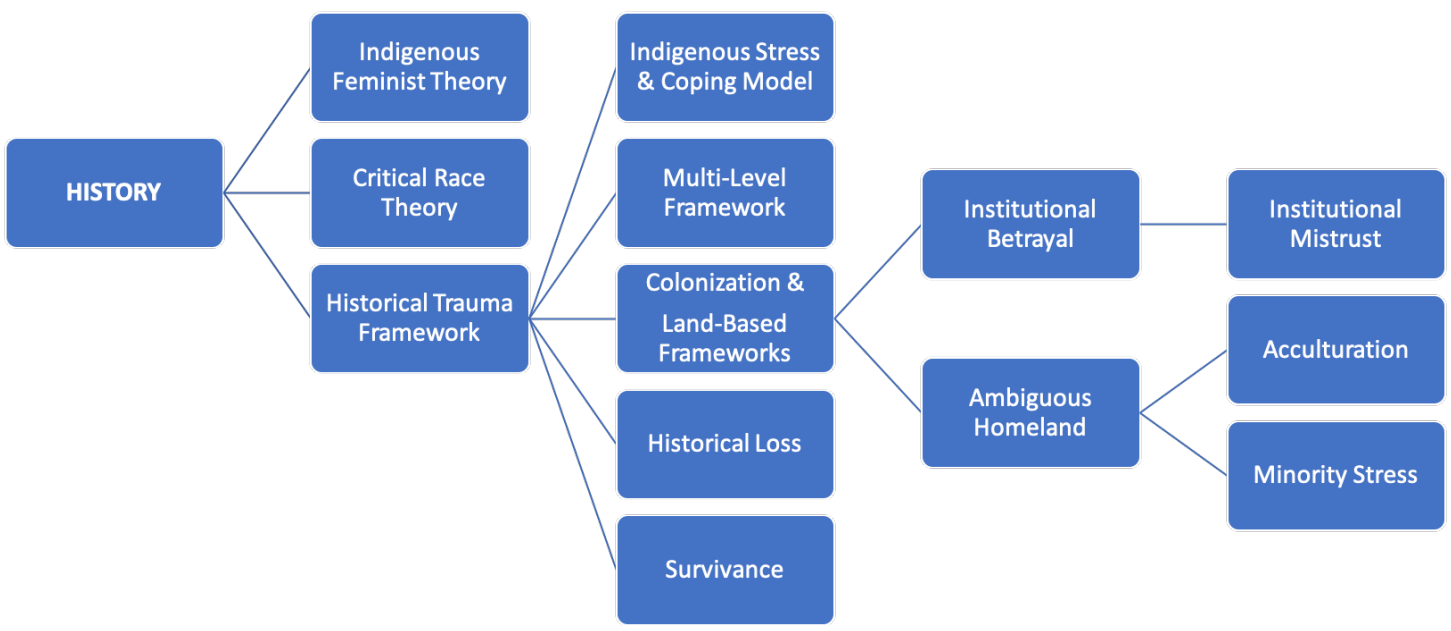

Figure 2. Map of Theoretical Frameworks.

\subsection{Thematic Summary}

This set of sources discusses how historical trauma events (i.e., Spanish invasion, colonization, and US-Mexican war) laid the foundation for the current problems of IMA-US, 
including poverty, low educational attainment, and limited access to adequate health-care services (Estrada 2009; Hanna et al. 2017; Ramirez and Hammack 2014; Stevens et al. 2015; Talebreza-May 2015; Zentella 2004, 2009, 2014). Many of the sources also provided integrative reviews of historical trauma research; these sources advocated for the use of the historical trauma framework in previously colonized populations, and extended the definition of indigenous to IMA-US, since they are descendants from the original inhabitants of the Americas (Brave Heart et al. 2011; Mohatt et al. 2014; Whitbeck et al. 2004). One dimension that all articles had in common was their focus on the HTEs of Mesoamerica and its effects on mental health. Highlights of these findings are presented in Table 2.

\subsection{Historical Traumatic Events and Impacts}

The series of traumatic events in the lifetime of IMA-US is extensive. History shows that Mexican people have only been free from major warfare for less than 100 out of the past 500 years (see Figure 1), not counting the many instances of internal rebellion, resistance, and subjugation of indigenous groups, farmer workers, and students by the federal governments (Bonfil Batalla 2020; Ramirez and Hammack 2014; Talebreza-May 2015; Zentella 2004) However, the cited literature only emphasizes three out of seven major HTEs relevant to IMA-US. Nevertheless, there is an extensive body of scholarly literature that has documented their history of collective trauma on both sides of the border (Bueno 2015; De la Peña 2006; Glenn and Tam 2004; Leon-Portilla 2011; Massey and Denton 1993; Revueltas et al. 1978; Vargas-Hernández 2005; Vasconcelos and González 1944). The impacts of the events reported in these works are discussed for a few subgroups within IMA-US, including Mexican, Mexican Indigenous, Mexican-American, Mexican-American Indigenous, and Californian Indians.

1. The invasion and colonisation of pre-colonial México (1519-1521)

The first major chapter of adversity for Mexican people started with the Spanish invasion (1519-1521). This period was characterized by their decimation, forced slavery, and the destruction of their cultural legacy, including writings, architecture, and artifacts (De la Peña 2006; Zentella 2009). This epistemicide also involved the suppression of mother tongues, culture, Indigenous identity, and wellness traditions. This invasion was followed by the colonial period, which lasted over 300 years, resulting in new mixed races, namely the Spanish-Indigenous, among many others (Anzaldúa et al. 2003; Hoskins and Padrón 2017; Zentella 2014).

2. The colonization (1521-1821)

After the invasion, the process of forced slavery ensued with the surviving indigenous peoples and the new racially mixed groups (e.g., Criollo, Mestizo, Castizo, Mulato) (see Appendix B Figure A2). These groups were forced to assimilate into Spanish culture, religion, and values; a process that promoted the erasure of their own indigenous heritage and identities (Anzaldúa et al. 2003; De la Peña 2006; Leon-Portilla 2011; Talebreza-May 2015; Zentella 2014). The erasure of indigenous ways of being and knowing (Smith 1999) did not end with the war of independence from Spain (1821) (De la Peña 2006). This process lasted thorough the colonial period and still prevails today. When México became a republic, the public educational system promoted the idea that the indigenous people had been largely eliminated during the Spanish invasion (Churchill 2000; Gutiérrez 2015). Even though Mexican Indigenous communities have made great advances to re-affirm their presence with the movement titled "estamos vivos/we are alive" (Morales 1989), much work still needs to be done to protect their rights, and validate their legacy and ways of knowing.

3. The US-Mexican war (1846-1848)

Another chapter in their lifetime trauma is described in the works that discuss the appropriation of the Mexican territory by the U. S. (see Appendix C Figure A3). This territorial transaction recorded in the Treaty of Guadalupe (Estrada 2009; TalebrezaMay 2015) led to many historical losses for Mexican and Indigenous communities: the loss of land, original identities, language, cultural knowledge, and family relationships, 
and brought about forced assimilation, and marginalization (Anzaldúa et al. 2003; Ramirez and Hammack 2014; Zentella 2009). Historical records report that the original inhabitants of the present-day U.S. Southwest were allowed to either keep their land and become U.S. citizens, or to relocate to Mexico across the the new border between the two countries (Massey and Denton 1993). The majority of Mexican nationals stayed in their residences and were granted U.S. citizenship, but their new citizenship was of a nominal nature, and property rights were violated for many, which led to the loss of their land and cultural resources (Anzaldúa et al. 2003; Estrada 2009; Ramirez and Hammack 2014; Talebreza-May 2015; Zentella 2004). Although the U.S. government promised to safeguard the property rights, language, and culture of the displaced communities, it did not uphold this part of the treaty (Estrada 2009).

During this this period, the cultural identities of the original inhabitants from the appropriated territory were fractured once again. Now the imposed identity was not indigenous versus Spaniard, or mestizo versus criollo, but Hispanic versus Chicano/Mexican-American. Even though these fractures to the collective identity have further suppressed their origin stories (Anzaldúa et al. 2003), throughout history, many of Mexican Indigenous communities have resisted assimilation. They have fought to retain their native identities and culture, often resorting to syncreticism. Syncreticism is the process of blending cultural practices from various traditions to ensure the continuity and transfer of knowledge (Cromer et al. 2018; Grayshield et al. 2015; Ramirez and Hammack 2014; Talebreza-May 2015). As result, current cultural traditions may resemble a fusion of elements taken from American Indians, Mexican immigrants, Spaniards, and Anglo Americans (Talebreza-May 2015).

4. Post-US-México War Era/ California Gold Rush.

The California Gold Rush is the saddest chapter in the history of adversity for Mexican descendants of the original inhabitants of present day Southwest (Ramirez and Hammack 2014). The California Indians endured colonial violence three times. First by Spain, then by the postcolonial government of México, and later by the U. S. (Estrada 2009; Ramirez and Hammack 2014; Talebreza-May 2015). When México lost roughly half of its territory to the United States, many of the native communities that had been already displaced and colonized by Spain faced a new wave of displacement and forced assimilation (Estrada 2009; Ramirez and Hammack 2014; Talebreza-May 2015). This time, they were forced to mirror the values and culture of the Anglo population (Anzaldúa et al. 2003; Ramirez and Hammack 2014; Talebreza-May 2015; Zentella 2009). They were persecuted and almost exterminated by brutal forms. However, elders in that community have preserved and transmitted narratives of survivance to younger generations, these inter-generational transmissions that have strengthen the Indigenous and resilient identity (Ramirez and Hammack 2014).

\subsection{Mechanisms of Transmission of Historical Trauma for IMA-US}

The selected sources did not present sufficient empirical evidence for mechanisms of transmission of trauma narratives for IMA-US. However, these sources discussed how narratives of HTEs have been recorded and preserved through archival documents, including oral tradition (Anzaldúa et al. 2003; Grayshield et al. 2015; Ramirez and Hammack 2014; Talebreza-May 2015; Zentella 2004), family systems (e.g., parenting) (Estrada 2009; Hanna et al. 2017; Stevens et al. 2015), and popular culture (Zentella 2014).

\section{Popular Culture}

Examples of transmission of both historical trauma and intergenerational resilience are readily evident in popular culture, such as art, dance, and music Zentella $(2004,2009$, 2014). Episodes from the Spanish invasion, colonization, and wars have been depicted in the muralismo movement. Muralismo is an artistic expression that typically depicts historical struggles as well as the resistance from Mestizo/Mexican and Indigenous groups Zentella $(2004,2009$, 2014). This art movement originated before the Mexican Revolution (1910), and included prominent Mexican painters such as Diego Rivera and 
José Clemente Orozco (Folgarait et al. 1998). Much of the work depicts the struggles of indigenous groups; and some work also addresses the pain associated with the traumatic origin of the Mexican people, the offspring of both aggressor and survivor (Anzaldúa et al. 2003). Additionally, this genre has also depicted a variety of social rights movements (Zentella 2004).

2. Collective Strength and Social Movements.

An extensive list of social movements carried out by IMA-US has been provided in Section 2.3.3. The movements cited in this literature included those led by Dolores Huerta and Cesar Chavez Zentella (2004, 2009, 2014). These activists opened up spaces to promote policy changes and raise awareness to the occupational injustices suffered by farm workers, a group composed mainly of mixed and non-mixed Indigenous Mexican families (Estrada 2009; Zentella 2004); however this group have also include people from other countries, such as Jamaica, the Philippines, Guatemala, Honduras (Johnson 1999; La Torre 2016). Additional sources capturing elements of the collective strength exhibited by this binational population includes local newsletters and newspapers. These include accounts of historical and contemporary oppression, as well as narratives of resistance and self-determination. Similar their stories have also been immortalized in the corridos Mexicanos. These are ballads that herald the actions of heroes/heroines who valiantly outwit the enemy, and the lyrics emphasize the resilient and humorous spirit of the Mexican people (Zentella 2004). The tradition of the corridos dates back several hundred years. This musical genre is mainly concerned with narrating traumatic events that affected large communities or groups by outsider agents (e.g., conquest/colonization, appropriation of Mexican territory, and struggles with border patrol) (Zentella 2004).

3. Family Systems/Parenting.

Stevens et al. (2015) builds on the literature that examines the transmission of historical trauma through parenting (Evans-Campbell 2008; Prussing 2014). Prior research has predominantly discussed links between intergenerational transmission of trauma and substance use problems (Corvo and Carpenter 2000; Evans-Campbell 2008; Walters and Simoni 2002). However, the authors cited here also discuss how parenting practices can convey to their offspring their sense of self-worth, mental health patterns, and behaviors. When the parents have been affected, directly or indirectly, by experiences resulted from traumatic events, such as child removal (Carvajal and Young 2009; Hanna et al. 2017; Stevens et al. 2015), land displacement (Estrada 2009; Ramirez and Hammack 2014; Talebreza-May 2015; Zentella 2004), and suppression of their native language, cultural beliefs and values (Anzaldúa et al. 2003; Brave Heart et al. 2011; Cromer et al. 2018; Estrada 2009).

According to the literature cited here, the impacts from these events, as well as the impacts and lessons during this era have been transmitted across generations; however, the stories associated with these transmissions have not always been transmitted. The disconnect in the stories shared between those affected communities and younger generations has been linked to psychological distress in current generations, which is harder to treat because these symptoms include an unidentified etiology. However, these family-level transmissions in research with related populations, have been discussed in terms of unresolved and disenfranchised grief disorders (Anzaldúa et al. 2003; Perez and Arnold-Berkovits 2018; Ramirez and Hammack 2014; Stevens et al. 2015; Talebreza-May 2015; Zentella 2014). The most recent chapter of adversity for IMA-US includes traumatic experiences due to forced family separation (Hondagneu-Sotelo and Avila 1997; Wells 2017), immigration related detention (Brabeck and Xu 2010), and deportation (Silver 2014). These disruptions in the parent-child relationship have been associated with a number of mental and behavioral health problems including depressive symptoms, health problems, decreased sense of wellness, guilt, anger and symptoms of posttraumatic stress disorder (Carvajal and Young 2009; Hanna et al. 2017; Ramirez and Ham- 
mack 2014; Stevens et al. 2015). These negative impacts are complex and not well understood, although the dynamics of powerlessness, self-worth, health problems, and substance use have been noted in the literature (Evans-Campbell 2008; Prussing 2014; Stevens et al. 2015). Less attention has been given to the review of positive cultural exchanges are disrupted when the bond between families is lost. This link is worth investigating because the impact does not only extend to parents and their offspring, but also to the parenting practices passed down across generations (Anzaldúa et al. 2003; Evans-Campbell 2008; Yehuda et al. 2001).

\subsection{Responses to Historical Trauma Events and Narratives for IMA-US}

Historical trauma responses, also known as colonial stress responses, have been defined as behavioral reactions to the atrocities of the colonial era (Evans-Campbell 2008). Historical trauma responses are not well known in the behavioral health literature for IMA-US. Even though research in related populations indicate a link between historical trauma and mental health and SUDs, this research has not been replicated for IMA-US. In general, behavioral health issues for IMA-US represent a public health concern, because the demands for specialty healthcare services exceed the available resources available to this population (Satcher 2000). Moreover, the number of qualified health care providers is also lagging (Gómez García et al. 2019). The works cited here discusses the dynamics that may play a role in health care disparities for IMA-US, mistrust in social welfare agencies and SUDs (Carvajal and Young 2009; Estrada 2009; Hanna et al. 2017; Stevens et al. 2015; TalebrezaMay 2015), these are discussed in the next section. Mistrust in social welfare agencies was discussed as both risk and protective factor. The discussion of adaptive mechanisms also included narratives of survivance, pride in ethnic heritage and identities, engagement in cultural practices (e.g., kinship, oral tradition, dance, storytelling, traditional health practices) and respect for elders, these topic is addressed in Section 4.7, which provides recommendations for healing from HT (Cromer et al. 2018; Grayshield et al. 2015; Ramirez and Hammack 2014).

1. Mistrust in Social Welfare Agencies.

Mistrust in governmental institutions was linked to both risk and protective health factors. In general, avoidance of services provided by social welfare agencies can lead to worsening health and unfulfilled social needs. However, when these services include a negative bias towards some population, this avoidance behavior may also serve as a protective factor (Estrada 2009; Talebreza-May 2015). Similarly to the way in which IMA-US are known to seek community and family bonds to enhance their well-being, they have also avoided contact with governmental welfare institutions to prevent harm (Carvajal and Young 2009; Estrada 2009; Hanna et al. 2017; Ramirez and Hammack 2014; Stevens et al. 2015). Several sources outlined a history of mistreatment towards IMA-US by social agencies and the medical industry (Estrada 2009; Ramirez and Hammack 2014; Talebreza-May 2015; Zentella 2004). This mistreatment was portrayed as disenfranchisement of basic human and property rights (Estrada 2009; Zentella 2014), inadequate health care services (Carvajal and Young 2009; Stevens et al. 2015; Talebreza-May 2015), and epistemological violence (Anzaldúa et al. 2003; Cromer et al. 2018; Grayshield et al. 2015). Whereas these sources did not present compelling empirical evidence to sustain these claims, other research has shown that when conditions of inequality and injustice are embedded in welfare institutions, the delivery of services become iatrogenic, worsening health outcomes for the affected populations (Battiste 2011; Suleman et al. 2018).

2. Mental Health Issues and SUDs.

In general, historical trauma research has discussed the impacts of historical trauma events on mental health and substance use for AIAN, however, this work is still developing. Empirical research addressing this topic for IMA-US is almost non-existent. As whole, the sources cited here do not present a coherent coverage on this subject. A few sources report behavioral health issues affecting IMA-US. When these findings were 
compared with supplementary literature, it was noted that prevalence rates between IMA-US and AIAN are similar. These complementary works also revealed a frequent theme: the uneven distribution of disease within IMA-US. The most marked differences were found between those born in the United States vs. foreign born. Similar patterns of difference were also identified between indigenous people of Mexican descent and their counterparts. Several studies found that indigenous people exhibit higher prevalence of behavioral health problems. The pronounced behavioral health issues for indigenous Mexican people is not surprising given that historically these groups have faced significantly greater barriers to public health programs compared with the mainstream population and other racial and ethnic groups (Fernandez 2019; Wallace and Castañeda 2010).

The average lifetime prevalence of any psychiatric or substance abuse disorder for individuals of Mexican descent was estimated at 36.7\%. The prevalence rate for those born in the US was higher, with an estimated rate of $47.6 \%$, compared to $28.5 \%$ for those born in México (Grant et al. 2004). Similarly, the prevalence of anxiety disorders was estimated at $16.3 \%$ for the US-born group, while the foreign-born reported a prevalence of $9.1 \%$ (Grant et al. 2004). The average prevalence rate of alcohol use disorders across U.S. and Mexican born groups was estimated at $21.9 \%$. The prevalence for those born in the US was estimated at 30.5\% and for the Mexican foreign-born population, this rate was reported at $15.3 \%$ (Grant et al. 2004). This pattern of increased vulnerability for US-born people of Mexican descent is also observed in the lifetime prevalence of any drug use disorders: the rate for people of Mexican descent born in the US was estimated at $12.0 \%$, while for foreign-born individuals the rate was estimated at $1.7 \%$, with an average rate across groups of $6.1 \%$ (Grant et al. 2004). Prior studies have reported similar findings in the Mexican population living in the US (Kessler et al. 2006). Research conducted in México yielded similar findings, with Mexican-born individuals reporting only half of the mental disorders reported by US-born people of Mexican descent (Breslau et al. 2007) Several studies report that the prevalence of alcohol and substance abuse disorders for Mexican migrant workers is higher for indigenous workers (9.9\%) than non-Indigenous workers (6.2\%) (Catalano et al. 2000; Fernandez 2019; Zúñiga et al. 2014). Complementary studies examining the health of migrant populations report similar findings in the patterns of substance use among Mexican migrants (Borges et al. 2016; Fernandez 2019; Zhang et al. 2015).

\subsection{Recommendations for Healing Historical Trauma}

1. Reconstructing Narratives of Survival.

Recent Indigenous scholarship highlights the importance of recreating narrative from traumatic historical events to disrupt the transmission of intergenerational trauma in Indigenous populations (Beltrán and Begun 2014; Evans-Campbell et al. 2006; Ortega-Williams et al. 2021). By recreating these stories, an opportunity arises to highlight the resources, allies, and resilience responses involved when confronting these stressful conditions (Cohen et al. 2012; White 1998). The sources cited here illustrate how the process of creating and sharing narratives of trauma and survival can be an effective way to elicit and appreciate adaptive responses (Cromer et al. 2018; Grayshield et al. 2015; Ramirez and Hammack 2014).

These works indicate that art, storytelling, and oral tradition are all ways in which IMA-US have preserved and transmitted these narratives. These narratives recount their history of adversity and collective strength, as well as vehicles of recovery from the effects of HTEs, with emphasis on traditional medicine and kinship (Anzaldúa et al. 2003; Grayshield et al. 2015; Hoskins and Padrón 2017). These cultural vehicles also have been used to retrace origin stories (Anzaldúa et al. 2003), and to reclaim indigenous identities and knowledge (Ramirez and Hammack 2014). The reviewed body of literature, and indeed this review itself, can also be seen as a contribution to this narrative. By tracing our own origin and synthesising traditional knowledge we 
are creating a new understandings about how our past has influenced our present (Pereyra 1980); especially the dynamics of health exchanges between IMA-US and social and healthcare organizations (Estrada 2009).

2. Community Engagement in the Development of Resilience-based Interventions.

The recommendations for healing from historical trauma include the importance of partnership with affected communities. Prior research has shown that community engagement in research process yields more comprehensive and sustainable interventions (Wallerstein and Duran 2010). These sources recommend engaging key stakeholders (i.e., parents, grandparents, local leaders) in the development of resilience-based interventions for younger generations (Cromer et al. 2018; Grayshield et al. 2015; Ramirez and Hammack 2014). Customarily, elders have played a vital role in the preservation and dissemination of cultural practices, including indigenous knowledge and traditions (Cromer et al. 2018; Grayshield et al. 2015; Ramirez and Hammack 2014). They also have played a role in the socialization of younger generations, particularly in nurturing intergenerational connections and fostering healing. These wellness, spiritual and traditional values and practices, have been disseminated through oral tradition. Findings from a small qualitative study conducted by Ramirez and Hammack (2014) suggest that the connection between the grandmothers and the youth was critical in the preservation of Indigenous identity.

The cited sources argue that elders possess a rich memory of the strengths and coping skills that have been crafted for many generations to deal with colonial oppression (Cromer et al. 2018; Grayshield et al. 2015; Ramirez and Hammack 2014). The authors hold that implementing engagement strategies rooted in the history, traditional beliefs, and health practices may result in higher retention rates in healthcare services, because these practices have a greater chance to be adopted by the users, since these have been embraced by these communities for many generations (Cromer et al. 2018; Grayshield et al. 2015; Ramirez and Hammack 2014).

3. Designing Therapeutic Spaces to Heal from Historical Trauma.

Another recommendation to recover from the consequences of historical trauma is through engagement of these communities in culturally appropriate treatment settings and modalities. Talebreza-May (2015) emphasized the need to design sanctuary spaces that are free from artifacts and behaviors resembling colonial ideology. Examples of elements that can foster safe spaces include the use of language, images, and concepts resembling the sentiments of the population for any significant historical events or milestones relevant to the target population. Most importantly, these therapeutic spaces must be created engaging expert knowledge on the historical experiences of the target population Hanna et al. (2017); Talebreza-May (2015); Zentella (2014).

\section{Discussion}

Over ten years ago, Estrada (2009) posed the question "can the concept of historical trauma be fruitfully applied to examine health issues among IMA-US?" This question has been answered affirmative by the works presented here. However, there are many more questions that follow. For example, can historical trauma research inform assessment, diagnosis and treatment for IMA-US? Can HT research help us to identify downstream manifestations of the denial of HTEs, resulting from unresolved grief? ${ }^{9}$ Would the validation of these trauma narratives provide an effective intervention, perhaps by restoring the right to grieve the collective losses resulting from these events? The reviewed sources convey the need to further examine this topic by discussing the impossibility of grieving, and articulating the suspicion that unresolved grief could potentially appear in alternative forms, such as attachment issues (Carvajal and Young 2009; Ramirez and Hammack 2014; Talebreza-May 2015), a sense of ambiguous loss of the homeland (Perez and Arnold-

9 Unresolved grief refers to forms of historical loss that emerge from the inability to voice historical trauma experiences (Brave Heart 1998). 
Berkovits 2018), other land-based disorders (Zentella 2004, 2009, 2014) and internalized oppression $^{10}$ (Estrada 2009).

This review introduces the term IMA-US. To the best of my knowledge there is no previous term that encompasses of all groups of Mexican descent. Each term carries a unique history of struggles and strengths. Whereas some terms emphasize a particular heritage (e.g., Indigenous, Spanish, Mexican, Mestizo), others tend to emphasize a resistance against anglocentric assimilation, such as Chicano/Xicano, La Raza (García 2020; Gimenez 1989; Saldaña-Portillo 2001; Vasconcelos 1993; Weaver 2001). However, terms such as Hispanic and Latino were associated with colonial connotations (Talebreza-May 2015; Zentella 2009 2014). Because the blending of a large number of nations into one group results the homogenizing of the populations represented in these categories (Battiste 2011; Okazaki et al. 2008; Tuck and Yang 2012). This aggregation of diverse nations results in the suppression of their unique histories and ethnic heritages, especially for nations with African and indigenous ancestry.

The emerging framework identified in this review moves away from prior westernbased Hispanic-Latinx scholarship into a more indigenous-based conceptualization for IMA-US. This historically grounded perspective reflects in the indigenous ancestry of the population, acknowledges their history of colonial trauma, and highlights their natural health resources. This conceptual proposition promotes social cohesion and healing from colonial legacy (Battiste 2011; de Sousa Santos 2015; Ortega-Williams et al. 2021; Saldaña-Portillo 2001; Smith 1999; Weaver 1992). The works cited here hypothesizes that if culturally-grounded health strengths are reinforced through resilience-based interventions, the outcomes of such interventions could provide an inoculation effect against historical and contemporary oppression on younger generations (Compton 2013; Kendi 2019; Vasquez 1998).

\subsection{Limitations of This Review}

Findings reported by these works have been criticized for having a selection bias: only those able to access research studies or healthcare services are represented in these studies (Escobar et al. 2000; Gee et al. 2006). Historically, IMA-US have struggled to secure adequate access to mainstream healthcare services and other social goods (Satcher 2000; Weinick et al. 2004). It is possible that selection bias causes systematic underestimation of the severity of behavioral problems for IMA-US, whereas measures of adversity that do not suffer from the same selection bias, such as limited access to education and healthcare or exposure to violence, are not underestimated. If studies addressing prevalence rates among IMA-US were conducted with a representative sample, the relationship between the severity of behavioral problems and their exposures to adverse conditions would be more clear (Borrell and Lancet 2012; Finlay and Agresti 1986; Griner and Smith 2006). This review does not address those problems of selection bias and leaves this issue for future work.

Whereas many innovative frameworks and concepts were introduced, the reviewed sources did not provide adequate empirical evidence to support their theoretical propositions. Major concepts salient in these works were only briefly mentioned in this review. These include complex unresolved grief (Grayshield et al. 2015; Ramirez and Hammack 2014; Stevens et al. 2015), aggressiveness in males as a colonial response (Talebreza-May 2015), identity disorders: split-mind disorder (Anzaldúa et al. 2003), Hispanidad as Jail Identity Zentella $(2009,2014)$, and and a wide range of land-based concepts, such as the concept of earth as motherland Zentella $(2009,2014)$, ambiguous loss of the homeland (Perez and ArnoldBerkovits 2018), and cultural trauma (Talebreza-May 2015). Health care disparity disorders, such as institutional mistrust were not explained in detail (Hanna et al. 2017; Perez and Arnold-Berkovits 2018; Talebreza-May 2015). The topic of health advantages resulting from the legacy of resistance and expressed through survivance is worthy of a review of its own

10 Internalize oppression occurs when those affected by colonial trauma internalize the views of the oppressor (Anzaldúa et al. 2003; Estrada 2009). 
(Cromer et al. 2018; Grayshield et al. 2015; Ramirez and Hammack 2014; Talebreza-May 2015).

\subsection{Conclusions}

The historically-grounded research reviewed here provides rich archival evidence of the history of colonial trauma for IMA-US. This work suggests that underutilization of social and healthcare services reflects historically motivated mistrust in social welfare institutions. This is congruent with findings in ethics, sociology and history literature (Cacari-Stone and Avila 2012; Glenn and Tam 2004; McLaren 2007). The small but growing body of research synthesized and interpreted here, makes the case that a historical perspective in the study any population with traumatic histories is essential for optimal diagnosis and treatment (Brave Heart et al. 2011; Kirmayer et al. 2011; Mohatt et al. 2014). Examining narratives of past mass trauma may be especially relevant in the conceptualization of health interventions for previously colonized groups (Brave Heart et al. 2011; Evans-Campbell 2008; Gone 2013; Kirmayer et al. 2011). For IMA-US, these trauma narratives have been depicted in traditional music, paintings, and in the social discourse, among other venues (Anzaldúa et al. 2003; Cromer et al. 2018; Grayshield et al. 2015; Ramirez and Hammack 2014; Zentella 2004, 2014). These cultural sources and artifacts shed light on the prevalence of historical trauma recollections in their collective memory (Van Dijk 1983; Zentella 2004, 2009, 2014). IMA-US have contributed significantly to the economic, intellectual, social, and cultural life of the United States. If the systemic barriers to accessing adequate healthcare services are not comprehensively addressed, the health disparities may worsen for all, but especially for those subgroups with higher rates of mental and/or substance use disorders (Krieger et al. 2010).

\subsection{Future Research}

As the IMA-US population continues to grow it becomes increasingly important to ensure their access to trusting and effective behavioral health care services. One way to do this is by conducting empirical studies to test the innovative resilience-based models suggested by the selected literature. Another way to advance this research is by replicating studies that tested historical trauma measurements with related populations (Walters et al. 2011 2020; Whitbeck et al. 2004). Additionally, investigating the perception of IMA-US with regards to healthcare service delivery policies may prove instrumental in engaging and retaining IMA-US in clinical treatment. Such efforts could be enhanced by establishing partnerships with key members of target communities (Wallerstein and Duran 2010). These stakeholders could collaborate in the development of interventions that reflect wellness resources within the communities (Cromer et al. 2018; Grayshield et al. 2015; Ramirez and Hammack 2014). Learning about specific health beliefs, values, attitudes, and practices of target communities can reveal important mechanisms of well-being that have prevailed throughout history. IMA-US have shown remarkable survival skills to preserve their lives, health, language, and culture. Perhaps research about the resilience of this population can help us to gain insight into other BIPOC groups with similar historical backgrounds. Although IMA-US may not share a unified history with related groups, it does share a few identities: the identity of the oppressed (Estrada 2009; Freire 2018; Sandoval 2013), the immigrant identity (Perez and Arnold-Berkovits 2018), and the identity of survivance (Ortega-Williams et al. 2021; Ramirez and Hammack 2014; Talebreza-May 2015).

This review emphasizes that IMA-US do not have one story, but many stories. They do not have one identity but multiple identities. All of the voices held by IMA-US are needed to provide a more comprehensive perspective on their health needs and outcomes. Throughout the years IMA-US have embraced different identities to ensure survival and social wellbeing. They have mobilized change by using their collective strength through inter-group alliances. Although their wellbeing is jeopardized by marked health disparities, an understanding of the collective health advantages of IMA-US may provide a focal point to forge a new alliance around health equality for all. 
Funding: This research received no external funding.

Institutional Review Board Statement: Not applicable.

Informed Consent Statement: Not applicable.

Conflicts of Interest: The author declare no conflict of interest.

Appendix A. PICo Framework for Qualitative Studies, Adapted by Murdoch University

\section{University Library}

PICo Worksheet and Search Strategy Protocol

1. Define your question using PICo by identifying: Population, Interest, and Context:

Population:

Interest:

Context:

Write out your question:

2. Type of study - methodology

List specific qualitative search terms or filters

3. Type of study - data collection

List types of data collection instruments:

4. List main topics and alternate terms from your PICo question that can be used for your search:

5. Write out your search strategy:

6. List any limits that may apply to your search:

Age:

Year(s) of publication:

Language(s):

7. List the databases you will search:

This form is adapted from: Miller, S.A. (2001). PICO worksheet and search strategy. US National Center for Dental Hygiene Research.

Figure A1. PICo Framework, adapted by Murdoch University. 
Appendix B. The PostColonial Caste System

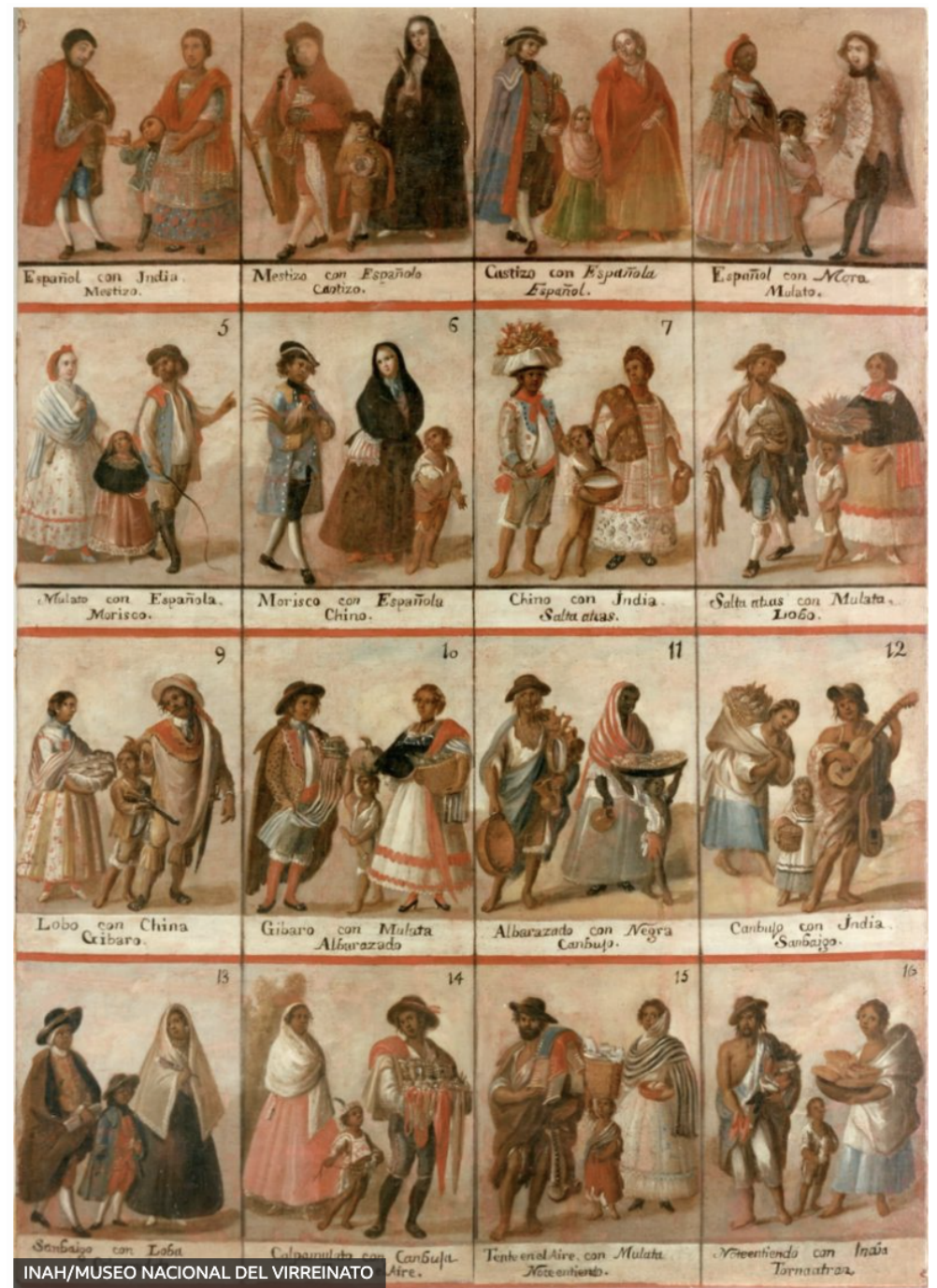

Figure A2. Castas de México.

Appendix C. Map of the Mexican Territory's Cessation to the United States

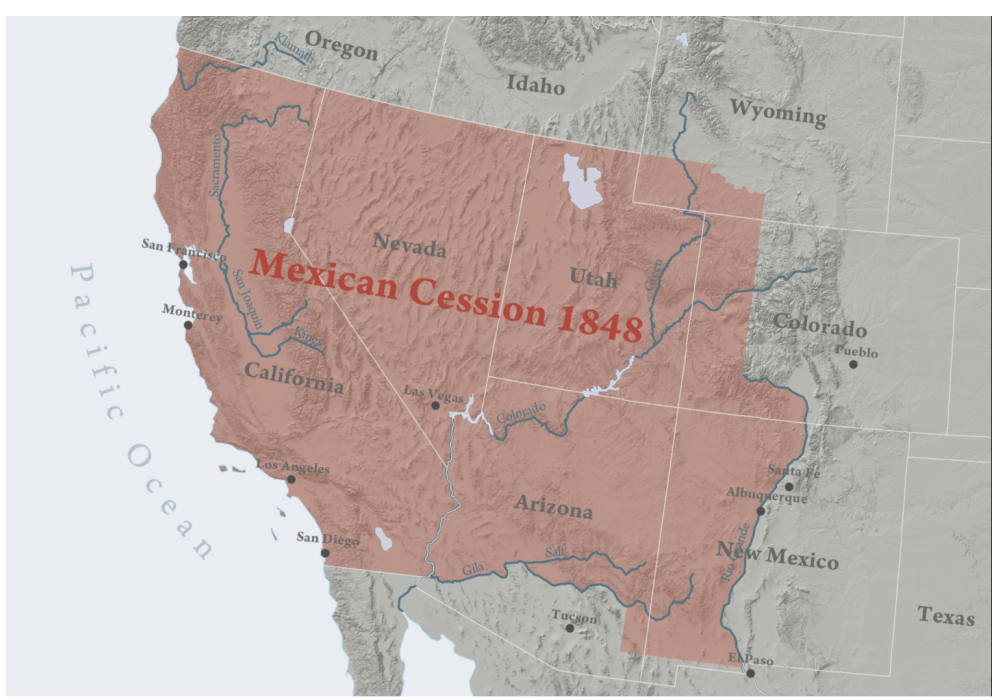

Figure A3. Mexican Cessions (1848). 


\section{References}

Aguilar, Mauricio Domínguez, Federico Dickinson Bannack, and Ana García de Fuentes. 2013. Climate Change and Water Access Vulnerability in the Human Settlement Systems of Mexico: The Merida Metropolitan Area, Yucatan. Realidad, Datos y Espacio Revista Internacional de Estadística y Geografía 4: 14-41.

Alarcón, Renato D., Amrita Parekh, Milton L. Wainberg, Cristiane S. Duarte, Ricardo Araya, and María A. Oquendo. 2016. Hispanic immigrants in the USA: Social and mental health perspectives. The Lancet Psychiatry 3: 860-70. [CrossRef]

Albertani, Claudio. 1999. Los pueblos Indígenas y la ciudad de México. una aproximación. Política y Cultura 12: 195-221.

Alegría, Margarita, Norah Mulvaney-Day, Maria Torres, Antonio Polo, Zhun Cao, and Glorisa Canino. 2007. Prevalence of psychiatric disorders across Latino subgroups in the United States. American Journal of Public Health 97: 68-75. [CrossRef] [PubMed]

Alegría, Margarita, and Meghan Woo. 2009. Conceptual Issues in Latino Mental Health. Los Angeles and Thousand Oaks: Sage Publications, Inc.

Alvarez, Josefina, Bradley D. Olson, Leonard A. Jason, Margaret I. Davis, and Joseph R. Ferrari. 2004. Heterogeneity Among Latinas and Latinos entering substance abuse treatment: Findings from a National Database. Journal of Substance Abuse Treatment 26: 277-84. [CrossRef]

Antebi, Susan. 2008. A Tiger in the Tank: A Literary Genetics of the Mexican Axolotl. Latin American Literary Review 36: 75-98.

Anzaldúa, Gloria E., Simon J. Ortiz, Inéz Hernández-Avila, and Domino Perez. 2003. Speaking across the divide. Studies in American Indian Literatures 15: 7-22.

Arksey, Hilary, and Lisa O'Malley. 2005. Scoping studies: Towards a methodological framework. International Journal of Social Research Methodology 8: 19-32. [CrossRef]

Barnhardt, Ray. 2005. Indigenous knowledge systems and alaska native ways of knowing. Anthropology E Education Quarterly 36: 8-23.

Barocas, Harvey A., and Carol B. Barocas. 1979. Wounds of the fathers: The next generation of holocaust victims. International Review of Psycho-Analysis 6: 331-40.

Barrera, Irán, and Denise Longoria. 2018. Examining cultural mental health care barriers among Latinos. CLEARvoz Journal 4: 1-12.

Battiste, Marie. 2011. Reclaiming Indigenous Voice and Vision. Vancouver: UBC Press.

Beltrán, Ramona, Antonia R.G. Alvarez, Angela R. Fernandez, Xochilt Alamillo, and Lisa Colón. 2021. Salud, cultura, tradición: Findings from an Alcohol and other drug and HIV needs assessment in Urban "Mexican American Indian" communities. Journal of Ethnic \& Cultural Diversity in Social Work 30: 62-79.

Beltrán, Ramona, and Stephanie Begun. 2014. 'It is medicine' narratives of healing from the aotearoa digital storytelling as indigenous media project (adsimp). Psychology and Developing Societies 26: 155-79. [CrossRef]

Bonfil Batalla, Guillermo. 2020. México Profundo: Una Civilización Negada. Tlalpan: Fondo de Cultura Económica.

Borges, Guilherme, Cheryl J. Cherpitel, Ricardo Orozco, Sarah E. Zemore, Lynn Wallisch, Maria-Elena Medina-Mora, and Joshua Breslau. 2016. Substance use and cumulative exposure to American society: Findings from both sides of the US-México border region. American Journal of Public Health 106: 119-27. [CrossRef] [PubMed]

Borjas, George J., and Lawrence F. Katz. 2007. The evolution of the Mexican-born workforce in the United States. In Mexican Immigration to the United States. Chicago: University of Chicago Press, pp. 13-56.

Borrell, Luisa N., and Elizabeth A. Lancet. 2012. Race/ethnicity and all-cause mortality in US adults: Revisiting the Hispanic paradox. American Journal of Public Health 102: 836-43. [CrossRef] [PubMed]

Brabeck, Kalina, and Qingwen Xu. 2010. The impact of detention and deportation on latino immigrant children and families: A quantitative exploration. Hispanic Journal of Behavioral Sciences 32: 341-61. [CrossRef]

Brandes, Stanley. 1998. The day of the dead, halloween, and the quest for mexican national identity. Journal of American Folklore 111: 359-80. [CrossRef]

Brave Heart, Maria Yellow Horse. 1998. The return to the sacred path: Healing the historical trauma and historical unresolved grief response among the Lakota through a psychoeducational group intervention. Smith College Studies in Social Work 68: 287-305. [CrossRef]

Brave Heart, Maria Yellow Horse, Josephine Chase, Jennifer Elkins, and Deborah B. Altschul. 2011. Historical trauma among Indigenous peoples of the Americas: Concepts, research, and clinical considerations. Journal of Psychoactive Drugs 43: 282-90. [CrossRef] [PubMed]

Breslau, Joshua, Sergio Aguilar-Gaxiola, Guilherme Borges, Ruby Cecilia Castilla-Puentes, Kenneth S. Kendler, Maria-Elena MedinaMora, Maxwell Su, and Ronald C. Kessler. 2007. Mental disorders among english-speaking mexican immigrants to the us compared to a national sample of mexicans. Psychiatry Research 151: 115-22. [CrossRef]

Broda, Johanna. 2003. La ritualidad mesoamericana y los procesos de sincretismo y reelaboración simbólica después de la conquista. Graffylia 2: 14-28.

Bueno, Christina. 2015. Indigenismo. The Wiley Blackwell Encyclopedia of Race, Ethnicity, and Nationalism 1-2. [CrossRef]

Caballero-Hoyos, Ramiro, Alberto Villasenor-Sierra, Rebeca Millán-Guerrero, Benjamín Trujillo-Hernández, and Joel Monárrez-Espino. 2013. Sexual risk behavior and type of sexual partners in transnational indigenous migrant workers. AIDS and Behavior 17: 1895-905. [CrossRef] [PubMed]

Cabassa, Leopoldo J., Roberto Lewis-Fernández, Shuai Wang, and Carlos Blanco. 2017. Cardiovascular disease and psychiatric disorders among Latinos in the United States. Social Psychiatry and Psychiatric Epidemiology 52: 837-46. [CrossRef] [PubMed] 
Cacari-Stone, Lisa, and Magdalena Avila. 2012. Rethinking research ethics for latinos: The policy paradox of health reform and the role of social justice. Ethics \& Behavior 22: 445-60.

Caminero-Santangelo, Marta. 2004. “Jasón's indian": Mexican americans and the denial of indigenous ethnicity in anaya's bless me, ultima. Critique: Studies in Contemporary Fiction 45: 115-28. [CrossRef]

Carvajal, Scott C., and Robert S. Young. 2009. Culturally based substance abuse treatment for american indians/alaska natives and latinos. Journal of Ethnicity in Substance Abuse 8: 207-22. [CrossRef] [PubMed]

Castro, Felipe González, Julie Garfinkle, Diana Naranjo, Maria Rollins, Judith S. Brook, and David W. Brook. 2007. Cultural traditions as "protective factors" among latino children of illicit drug users. Substance Use E Misuse 42: 621-42.

Catalano, Ralph, Ethel Aldrete, William Vega, Bohdan Kolody, and Sergio Aguilar-Gaxiola. 2000. Job loss and major depression among Mexican Americans. Social Science Quarterly 81: 477-88.

Chambers, Lori A., Randy Jackson, Catherine Worthington, Ciann L. Wilson, Wangari Tharao, Nicole R. Greenspan, Renee Masching, Valérie Pierre-Pierre, Tola Mbulaheni, Marni Amirault, and et al. 2018. Decolonizing scoping review methodologies for literature with, for, and by Indigenous peoples and the African diaspora: Dialoguing with the tensions. Qualitative Health Research 28: 175-88. [CrossRef]

Chan, Sucheng. 2000. A people of exceptional character: Ethnic diversity, nativism, and racism in the California gold rush. California History 79: 44-85. [CrossRef]

Chávez, Javier Gámez. 2015. Yaquis y magonistas: Una alianza indígena y popular en la revolución mexicana. La Pacarina del Sur 3: $1-22$.

Cheung, Freda K., and Lonnie R. Snowden. 1990. Community mental health and ethnic minority populations. Community Mental Health Journal 26: 277-91. [CrossRef] [PubMed]

Churchill, Nancy E. 2000. Erasing popular history: State Discourse of Cultural Patrimony in Puebla, Mexico. Paper presented at XXII International Congress of the Latin American Studies Association, Miami, FL, USA, March 16-18.

Clarke, Victoria, Virginia Braun, and Nikki Hayfield. 2015. Thematic analysis. In Qualitative Psychology: A Practical Guide to Research Methods. Thousand Oaks: Sage, pp. 222-48.

Coffey, Amanda, and Paul Atkinson. 1996. Making Sense of Qualitative Data: Complementary Research Strategies. Thousand Oaks: Sage Publications, Inc.

Cohen, Judith A., Anthony P. Mannarino, Matthew Kliethermes, and Laura A. Murray. 2012. Trauma-focused cbt for youth with complex trauma. Child Abuse E Neglect 36: 528-41.

Cohen-Chen, Smadar, and Martijn Van Zomeren. 2018. Yes we can? group efficacy beliefs predict collective action, but only when hope is high. Journal of Experimental Social Psychology 77: 50-59. [CrossRef]

Cohn, Diana, and Francisco Delgado. 2005. Si, Se Puede!/Yes, We Can! El Paso: Cinco Puntos Press.

Comas-Diaz, Lillian. 2001. Hispanics, Latinos, or Americanos: The evolution of identity. Cultural Diversity and Ethnic Minority Psychology 7: 115. [CrossRef]

Compton, Josh. 2013. Inoculation theory. In The Sage Handbook of Persuasion: Developments in Theory and Practice. Los Angeles: Sage Publications Inc., vol. 2, pp. 220-37.

Cortázar, Julio. 2015. Axolotl. Stockholm: Modernista.

Corvo, Kenneth, and Elizabeth H. Carpenter. 2000. Effects of parental substance abuse on current levels of domestic violence: A possible elaboration of intergenerational transmission processes. Journal of Family Violence 15: 123-35. [CrossRef]

Creswell, John W., and J. David Creswell. 2017. Research Design: Qualitative, Quantitative, and Mixed Methods Approaches. Los Angeles: Sage Publications.

Cromer, Lisa Demarni, Mary E. Gray, Ludivina Vasquez, and Jennifer J. Freyd. 2018. The Relationship of Acculturation to Historical Loss Awareness, Institutional Betrayal, and the Intergenerational Transmission of Trauma in the American Indian Experience. Journal of Cross-Cultural Psychology 49: 99-114. [CrossRef]

Damschroder, Laura J., David C. Aron, Rosalind E. Keith, Susan R. Kirsh, Jeffery A. Alexander, and Julie C. Lowery. 2009. Fostering implementation of health services research findings into practice: A consolidated framework for advancing implementation science. Implementation Science 4: 1-15. [CrossRef]

De la Peña, Guillermo. 2002. La educación indígena. Consideraciones críticas. Sinéctica, Revista Electrónica de Educación $20: 46-53$.

De la Peña, Guillermo. 2006. A new Mexican nationalism? Indigenous rights, constitutional reform and the conflicting meanings of multiculturalism. Nations and Nationalism 12: 279-302. [CrossRef]

de Sousa Santos, Boaventura. 2015. Epistemologies of the South: Justice against Epistemicide. New York: Routledge. [CrossRef]

Drisko, James W. 1997. Strengthening qualitative studies and reports: Standards to promote academic integrity. Journal of Social Work Education 33: 185-97. [CrossRef]

Duran, Eduardo. 1995. Native American Postcolonial Psychology. Albany: State University of New York Press.

Duran, Eduardo, Bonnie Duran, Maria Yellow Horse Brave-Heart, and Susan Yellow Horse-Davis. 1998. Healing the American Indian soul wound. In International Handbook of Multigenerational Legacies of Trauma. New York: Plenum Press, pp. 341-54.

Eisenstadt, Todd A. 2011. Politics, Identity, and Mexico's Indigenous Rights Movements. Cambridge: Cambridge University Press.

Escobar, Javier I., Constanza Hoyos Nervi, and Michael A. Gara. 2000. Immigration and mental health: Mexican americans in the united states. Harvard Review of Psychiatry 8: 64-72. [CrossRef] [PubMed] 
Estrada, Antonio L. 2009. Mexican Americans and historical trauma theory: A theoretical perspective. Journal of Ethnicity in Substance Abuse 8: 330-40. [CrossRef]

Evans-Campbell, Teresa. 2008. Historical trauma in American Indian/Native Alaska communities: A multilevel framework for exploring impacts on individuals, families, and communities. Journal of Interpersonal Violence 23: 316-38. [CrossRef]

Evans-Campbell, Teresa, Taryn Lindhorst, Bu Huang, and Karina L. Walters. 2006. Interpersonal violence in the lives of urban american indian and alaska native women: Implications for health, mental health, and help-seeking. American Journal of Public Health 96 : 1416-22. [CrossRef]

Fabrega, Horacio, Jr. 1990. Hispanic mental health research: A case for cultural psychiatry. Hispanic Journal of Behavioral Sciences 12: 339-65. [CrossRef]

Farley, Reynolds, and John Haaga. 2005. The American People: Census 2000. New York: Russell Sage Foundation.

Fernandez, Angela. 2019. "Wherever I Go, I Have It inside of Me": Indigenous Cultural Dance as a Transformative Place of Health and Prevention for Members of an Urban Danza Mexica Community. Ph.D. thesis, University of Washington, Washington, DC, USA.

Ferrari, Rossella. 2015. Writing narrative style literature reviews. Medical Writing 24: 230-35. [CrossRef]

Ferriss, Susan, and Ricardo Sandoval. 1997. The Fight in the Fields: Cesar Chavez and the Farmworkers Movement. Boston: Houghton Mifflin Harcourt.

Finlay, Barbara, and A. Agresti. 1986. Statistical Methods for the Social Sciences. San Francisco: Dellen.

Flores, Antonio. 2017. How the Us Hispanic Population Is Changing. Washington, DC: Pew Research Center, vol. 18.

Folgarait, Leonard, José Clemente Orozco, Diego Rivera, and David Alfaro Siqueiros. 1998. Mural Painting and Social Revolution in Mexico, 1920-1940: Art of the New Order. Cambridge: Cambridge University Press.

Fox, Jonathan, and Gaspar Rivera-Salgado. 2004. Indigenous Mexican Migrants in the United States. San Diego: University of California, Center for US-Mexican Studies and Center for Comparative Immigration Studies. [CrossRef]

Frankl, Viktor E. 2011. Man's Search for Ultimate Meaning. New York: Random House.

Freire, Paulo. 2018. Pedagogy of the Oppressed. New York: Bloomsbury Publishing USA.

García, Ivis. 2020. Cultural insights for planners: Understanding the terms Hispanic, Latino, and Latinx. Journal of the American Planning Association 86: 393-402. [CrossRef]

Garduño, Everardo. 2004. Cuatro ciclos de resistencia indígena en la frontera méxico-estados unidos. Revista Europea de Estudios Latinoamericanos y del Caribe/European Review of Latin American and Caribbean Studies 77: 41-60. [CrossRef]

Gee, Gilbert C., Andrew Ryan, David J. Laflamme, and Jeanie Holt. 2006. Self-reported discrimination and mental health status among African descendants, Mexican Americans, and other Latinos in the New Hampshire REACH 2010 Initiative: The added dimension of immigration. American Journal of Public Health 96: 1821-28. [CrossRef] [PubMed]

Gimenez, Martha E. 1989. Latino/"hispanic" —Who needs a name? The case against a standardized terminology. International Journal of Health Services 19: 557-71. [CrossRef]

Ginorio, Angela, and Michelle Huston. 2001. Si, Se Puede! Yes, We Can: Latinas in School. ERIC. Available online: https: / / eric.ed.gov / ?id=ED452330 (accessed on 29 September 2020).

Glenn, Evelyn N., and Sandra Tam. 2004. Unequal freedom: How race and gender shaped american citizenship and labour. Canadian Woman Studies 23: p. 172.

Gómez García, Rogelio, Margarita Alonso Sangregorio, and María Lucía Llamazares Sánchez. 2019. Factorial validity of the maslach burnout inventory-human services survey (mbi-hss) in a sample of spanish social workers. Journal of Social Service Research 45: 207-19. [CrossRef]

Gone, Joseph P. 2013. Redressing First Nations historical trauma: Theorizing mechanisms for Indigenous culture as mental health treatment. Transcultural Psychiatry 50: 683-706. [CrossRef]

Gonzalez-Barrera, Ana, and Mark Hugo Lopez. 2013. A Demographic Portrait of Mexican-Origin Hispanics in the United States. Washington, DC: Pew Hispanic Center.

González de Alba, Iván Guillermo. 2010. Poverty in Mexico from an ethnic perspective. Journal of Human Development and Capabilities 11: 449-65. [CrossRef]

Grant, Bridget F., Frederick S. Stinson, Deborah S. Hasin, Deborah A. Dawson, S. Patricia Chou, and Karyn Anderson. 2004. Immigration and lifetime prevalence of DSM-IV psychiatric disorders among Mexican Americans and non-Hispanic whites in the United States: Results from the national epidemiologic survey on alcohol and relatedconditions. Archives of General Psychiatry 61: 1226-33. [CrossRef]

Grayshield, Lisa, Jeremy J. Rutherford, Sibella B. Salazar, Anita L. Mihecoby, and Laura L. Luna. 2015. Understanding and healing historical trauma: The perspectives of Native American elders. Journal of Mental Health Counseling 37: 295-307. [CrossRef]

Green, Bart N., Claire D. Johnson, and Alan Adams. 2006. Writing narrative literature reviews for peer-reviewed journals: secrets of the trade. Journal of Chiropractic Medicine 5: 101-17. [CrossRef]

Greene, Judith. 2018. Confronting Immigration Enforcement under Trump. Social Justice 45: 83-98.

Griner, Derek, and Timothy B. Smith. 2006. Culturally adapted mental health intervention: A meta-analytic review. Psychotherapy: Theory, Research, Practice, Training 43: 531. [CrossRef]

Guilamo-Ramos, Vincent, Andrew Hidalgo, and Lance Keene. 2020. Consideration of Heterogeneity in a Meta-analysis of Latino Sexual Health Interventions. Pediatrics 146: e20201406. [CrossRef] [PubMed] 
Gutiérrez, Gerardo. 2015. Identity erasure and demographic impacts of the Spanish caste system on the Indigenous populations of México. In Beyond Germs: Native Depopulation in North America. Tucson: University of Arizona Press, pp. 119-45.

Gy, Pierre M. 1992. Sampling of Heterogeneous and Dynamic Material Systems: Theories of Heterogeneity, Sampling and Homogenizing. Amsterdam: Elsevier.

Hanna, Karen B. 2017. A call for healing: Transphobia, homophobia, and historical trauma in filipina/o/x american activist organizations. Hypatia 32: 696-714. [CrossRef]

Hanna, Michele D., Erin R. Boyce, and Jessica Yang. 2017. The impact of historical trauma and mistrust on the recruitment of resource families of color. Adoption Quarterly 20: 65-82. [CrossRef]

Harding, Sandra. 1992. Rethinking standpoint epistemology: What is "strong objectivity?". The Centennial Review 36: 437-70.

Harding, Sandra G. 2004. The Feminist Standpoint Theory Reader: Intellectual and Political Controversies. New York: Routledge.

Henry, James Paget, and Patricia M. Stephens. 2013. Stress, Health, and the Social Environment: A Sociobiologic Approach to Medicine. New York: Springer-Verlag Science \& Business Media.

Hernández, Leandra Hinojosa. 2019. Feminist approaches to border studies and gender violence: Family separation as reproductive injustice. Women's Studies in Communication 42: 130-34. [CrossRef]

Hondagneu-Sotelo, Pierrette, and Ernestine Avila. 1997. "I'm here, but i'm there" the meanings of latina transnational motherhood. Gender E Society 11: 548-71.

Honebein, Peter C. 1996. Seven goals for the design of constructivist learning environments. In Constructivist Learning Environments: Case Studies in Instructional Design. Englewood Cliffs: Educational Technology Publications, Inc., pp. 11-24.

Hoskins, David, and Elena Padrón. 2017. The practice of curanderismo: A qualitative study from the perspectives of curandera/os. Journal of Latina/o Psychology 6: 79. [CrossRef]

Huirimilla, Juan Paulo. 2007. "Zapatismo: Democracia, libertad y justicia”. (entrevista a amado lascar). Alpha (Osorno) 24: 227-37. [CrossRef]

Humes, Karen R., Nicholas A. Jones, and Roberto R. Ramirez. 2011. Overview of Race and Hispanic Origin: 2010. Washington, DC: US Department of Commerce, Economics and Statistics Administration.

Hunt, Linda M., Suzanne Schneider, and Brendon Comer. 2004. Should "acculturation" be a variable in health research? A critical review of research on US Hispanics. Social Science E Medicine 59: 973.

INEGi XII. 2001. Censo General de Población y Vivienda 2000. Available online: http://www.inegi.gob.mx/est/default.asp (accessed on 15 September 2019).

Intrator, Jake, Jonathan Tannen, and Douglas S. Massey. 2016. Segregation by race and income in the United States 1970-2010. Social Science Research 60: 45-60. [CrossRef] [PubMed]

Johnson, Don H. 2006. Signal-to-noise ratio. Scholarpedia 1: 2088. [CrossRef]

Johnson, Kevin R. 1999. Celebrating latcrit theory: What do we do when the music stops. UC Davis School of Law $33: 753$.

Johnson, Taylor N. 2019. The dakota access pipeline and the breakdown of participatory processes in environmental decision-making. Environmental Communication 13: 335-52. [CrossRef]

Kendi, Ibram X. 2019. How to Be An Antiracist. New York: One World.

Kessler, Ronald C., Hagop S. Akiskal, Minnie Ames, Howard Birnbaum, Paul Greenberg, Robert M. A. Hirschfeld, Robert Jin, Kathleen R. Merikangas, Gregory E. Simon, and Philip S. Wang. 2006. Prevalence and effects of mood disorders on work performance in a nationally representative sample of us workers. American Journal of Psychiatry 163: 1561-68. [CrossRef]

Kindig, David, and Greg Stoddart. 2003. What is population health? American Journal of Public Health 93: 380-83. [CrossRef]

Kirmayer, Laurence J., Stéphane Dandeneau, Elizabeth Marshall, Morgan Kahentonni Phillips, and Karla Jessen Williamson. 2011. Rethinking resilience from Indigenous perspectives. The Canadian Journal of Psychiatry 56: 84-91. [CrossRef]

Kirmayer, Laurence J., Stéphane Dandeneau, Elizabeth Marshall, Morgan Kahentonni Phillips, and Karla Jessen Williamson. 2012. Toward an ecology of stories: Indigenous perspectives on resilience. In The Social Ecology of Resilience. New York: Springer, pp. 399-414.

Krieger, Nancy, Margarita Alegría, Naomar Almeida-Filho, Jarbas Barbosa da Silva, Maurício L. Barreto, Jason Beckfield, Lisa Berkman, Anne-Emanuelle Birn, Bruce B. Duncan, Saul Franco, and et al. 2010. Who, and what, causes health inequities? reflections on emerging debates from an exploratory latin american/north american workshop. Journal of Epidemiology E Community Health 64: 747-49.

Kumar, Satish, Claire Bellis, Mark Zlojutro, Phillip E. Melton, John Blangero, and Joanne E. Curran. 2011. Large scale mitochondrial sequencing in Mexican Americans suggests a reappraisal of Native American origins. BMC Evolutionary Biology 11: 293. [CrossRef]

La Torre, Joanna Catalina. 2016. Decolonizing and Re-Indigenizing Filipinos in Diaspora. Master's thesis, California State University, Sacramento, CA, USA.

Leaf, Philip J., Martha Livington Bruce, Gary L. Tischler, and Charles E. Holzer III. 1987. The relationship between demographic factors and attitudes toward mental health services. Journal of Community Psychology 15: 275-84. [CrossRef]

Leon-Portilla, Miguel. 2011. The Broken Spears: The Aztec Account of the Conquest of Mexico. Boston: Beacon Press.

Levac, Danielle, Heather Colquhoun, and Kelly K. O'Brien. 2010. Scoping studies: Advancing the methodology. Implementation Science: IS 5: 69. [CrossRef] [PubMed]

Maguire, Moira, and Brid Delahunt. 2017. Doing a thematic analysis: A practical, step-by-step guide for learning and teaching scholars. All Ireland Journal of Higher Education 9: 3. 
Martínez Coria, Ramón, and Jesús Armando Haro Encinas. 2015. Derechos territoriales y pueblos indígenas en méxico: Una lucha por la soberanía y la nación. Revista Pueblos y Fronteras Digital 10: 228-56. [CrossRef]

Massey, Douglas, and Nancy A. Denton. 1993. American apartheid: Segregation and the making of the underclass. Cambridge: Harvard University Press.

Matamoro, Blas. 1990. Diván de octavio paz. Hispamérica 19: 3-13.

McLaren, Lauren. 2007. Explaining mass-level euroscepticism: Identity, interests, and institutional distrust. Acta Politica 42: $233-51$. [CrossRef]

Mena Robles, Jorge, and Ruth Gomberg-Muñoz. 2016. Activism after daca: Lessons from chicago's immigrant youth justice league. North American Dialogue 19: 46-54. [CrossRef]

Mendoza, Zoila. 2001. Al Son de la Danza: Identidad y Comparsas en el Cuzco. Fondo Editorial. Lima: Pontificia Universidad Católica del Perú.

Miller, Syrene A. 2001. Pico Worksheet and Search Strategy. Cave Creek: National Center for Dental Hygiene Research.

Miller, Syrene A., and Jane L. Forrest. 2001. Enhancing your practice through evidence-based decision making: Pico, learning how to ask good questions. Journal of Evidence Based Dental Practice 1: 136-41. [CrossRef]

Mines, Richard, Sandra Nichols, and David Runsten. 2010. California's Indigenous Farmworkers. Final Report of the Indigenous Farmworker Study (IFS) to the California Endowment. Indigenous Mexicans in California Agriculture. Available online: http: / / indigenousfarmworkers.org (accessed on 29 September 2020).

Mingers, John. 2001. Combining is research methods: Towards a pluralist methodology. Information Systems Research 12: 240-59. [CrossRef]

Mohanty, Chandra. 1988. Under western eyes: Feminist scholarship and colonial discourses. Feminist Review 30: 61-88. [CrossRef]

Mohatt, Nathaniel Vincent, Azure B. Thompson, Nghi D. Thai, and Jacob Kraemer Tebes. 2014. Historical trauma as public narrative: A conceptual review of how history impacts present-day health. Social Science \& Medicine 106: 128-36. [CrossRef]

Morales, Daniel Eduardo Matul. 1989. Estamos vivos: Reafirmación de la cultura Maya. Nueva Sociedad 99: 147-57.

Morris, Michael W., Kwok Leung, Daniel Ames, and Brian Lickel. 1999. Views from inside and outside: Integrating emic and etic insights about culture and justice judgment. Academy of Management Review 24: 781-96. [CrossRef]

Morris, Patricia McGrath. 2002. The capabilities perspective: A framework for social justice. Families in Society 83: 365-73. [CrossRef]

Muñoz, Carlos. 2007. Youth, Identity, Power: The Chicano Movement. Brooklyn: Verso Trade.

Murphey, David, Lina Guzman, and Alicia Torres. 2014. America's Hispanic Children: Gaining Ground, Looking forward. Publication\# 2014-38. Bethesda: Child Trends.

Navarrete, Federico. 2004. Las Relaciones Interétnicas en México. Mexico City: Universidad Nacional Autónoma de México.

Navarrete, Federico. 2005. El mestizaje y las culturas regionales. Las Relaciones Interétnicas: Elective Course. Mexico: Universidad Nacional Autónoma de México. Available online: https:/ / red.pucp.edu.pe/ridei/files/2012/02/120203.pdf (accessed on 29 September 2020).

Nevitte, Neil. 2017. The North American Trajectory: Cultural, Economic, and Political Ties among the United States, Canada and Mexico. New York: Routledge.

Noe-Bustamante, Luis, Antonio Flores, and Sono Shah. 2019. Facts on Hispanics of Mexican origin in the United States, 2017. Pew Research Center 16: 2019.

Norris, Tina, Paula L. Vines, and Elizabeth M. Hoeffel. 2012. The American Indian and Alaska Native Population: 2010. Census Brief No. C2010BR-10.Available online: https: / / digitallibrary.utah.gov/awweb/awarchive?item=49864 (accessed on 29 September 2020).

Nurius, Paula S., and Charles P. Hoy-Ellis. 2013. Stress effects on health. Encyclopedia of Social Work. Available online: https: / / www.census.gov/prod/cen2010/briefs/c2010br-10.pdf (accessed on 29 September 2020).

Oehmichen, Cristina. 2007. Violencia en las relaciones interétnicas y racismo en la ciudad de méxico. Cultura y Representaciones Sociales 1: 91-117.

Okazaki, Sumie, E. J. R. David, and Nancy Abelmann. 2008. Colonialism and psychology of culture. Social and Personality Psychology Compass 2: 90-106. [CrossRef]

Oliva de Coll, Josefina. 1976. La resistencia indígena ante la conquista. Mexico City: Siglo Veintiuno.

Onwuegbuzie, Anthony J., Nancy L. Leech, and Kathleen M. T. Collins. 2012. Qualitative analysis techniques for the review of the literature. The Qualitative Report 17: 56.

Orozco-Hershey, Araceli. 2019. Conditional Class Regression: A Model Derived to Examine within Group Heterogeneity in Large Scale Studies with Latinx-Hispanic Data Sets [Poster session]. Paper presented at Society for Prevention Research 27th Annual Meeting, San Francisco, CA, USA May 28-31.

Ortega-Williams, Anna, Ramona Beltrán, Katie Schultz, Zuleka Ru-Glo Henderson, Lisa Colón, and Ciwang Teyra. 2021. An integrated historical trauma and posttraumatic growth framework: A cross-cultural exploration. Journal of Trauma E Dissociation 22: 220-40.

Ortiz, Laura Velasco. 2014. Transnational Ethnic Processes: Indigenous Mexican Migrations to the United States. Latin American Perspectives 41: 54-74. [CrossRef]

Patnaik, Esha. 2013. Reflexivity: Situating the researcher in qualitative research. Humanities and Social Science Studies 2: 98-106.

Peña, Guillermo de la. 2005. Social and cultural policies toward indigenous peoples: Perspectives from Latin America. Annual Review of Anthropology 34: 717-39.

Pereyra, Carlos. 1980. Historia, Para Qué? México City: Siglo XXI. 
Perez, Rose M., and Ilona Arnold-Berkovits. 2018. A Conceptual framework for understanding Latino immigrant's ambiguous loss of homeland. Hispanic Journal of Behavioral Sciences 40: 91-114. [CrossRef]

Peters, Micah D. J., Christina M. Godfrey, Hanan Khalil, Patricia McInerney, Deborah Parker, and Cassia Baldini Soares. 2015. Guidance for conducting systematic scoping reviews. International Journal of Evidence-based Healthcare 13: 141. [CrossRef] [PubMed]

Phillips, Russell E. 1978. Impact of nazi holocaust on children of survivors. American Journal of Psychotherapy 32: 370-78. [CrossRef]

Pihama, Leonie, Paul Reynolds, Cherryl Smith, John Reid, Linda Tuhiwai Smith, and Rihi Te Nana. 2014. Positioning historical trauma theory within aotearoa new zealand. AlterNative: An International Journal of Indigenous Peoples 10: 248-62. [CrossRef]

Pinedo, Miguel, Yasmin Campos, Daniela Leal, Julio Fregoso, Shira M. Goldenberg, and María Luisa Zúñiga. 2014. Alcohol use behaviors among indigenous migrants: A transnational study on communities of origin and destination. Journal of Immigrant and Minority Health 16: 348-55. [CrossRef]

Pokhrel, Pallav, and Thaddeus A. Herzog. 2014. Historical trauma and substance use among native hawaiian college students. American Journal of Health Behavior 38: 420-29. [CrossRef]

Posadas, Carlos A. Molina. 2012. Espacios de la mexicanidad. Espacialidades 2: 112-42.

Proctor, Enola, Hiie Silmere, Ramesh Raghavan, Peter Hovmand, Greg Aarons, Alicia Bunger, Richard Griffey, and Melissa Hensley. 2011. Outcomes for implementation research: Conceptual distinctions, measurement challenges, and research agenda. Administration and Policy in Mental Health and Mental Health Services Research 38: 65-76. [CrossRef]

Prussing, Erica. 2014. Historical trauma: Politics of a conceptual framework. Transcultural Psychiatry 51: 436-58. [CrossRef] [PubMed]

Ramirez, Lucio Cloud, and Phillip L. Hammack. 2014. Surviving colonization and the quest for healing: Narrative and resilience among California Indian tribal leaders. Transcultural Psychiatry 51: 112-33. [CrossRef] [PubMed]

Revueltas, José, Andrea Revueltas, and Philippe Cheron. 1978. México 68: Juventud y Revolución. Mexico: Ediciones Era, vol. 15.

Rickford, Russell. 2016. Black lives matter: Toward a modern practice of mass struggle. In New Labor Forum. Los Angeles: SAGE Publications, vol. 25, pp. 34-42.

Rizo, Elisa. 2003. Juan rulfo y la representación literaria del mestizaje. Escritos, Revista del Centro de Ciencias del Lenguaje 28: 125-48.

Rojas, Maythee. 2007. Re-Membering Josefa: Reading the Mexican female body in California gold rush chronicles. Women's Studies Quarterly 35: 126-48.

Rundle, Christopher. 2014. Theories and methodologies of translation history: The value of an interdisciplinary approach. The Translator 20: 2-8. [CrossRef]

Sahagún, Bernardino de, Arthur J. Anderson, and Charles E. Dibble. 1970. Florentine Codex: General History of the Things of New Spain. Santa Fe: NM School of American Research.

Saldaña-Portillo, Josefina. 2001. Who's the indian in aztlan? Re-writing mestizaje, indianism, and chicanismo from the lacandon. In The Latin American Subaltern Studies Reader. Durham: Duke University Press, pp. 402-23.

Sandoval, Anna Marie. 2009. Toward a Latina Feminism of the Americas: Repression and Resistance in Chicana and Mexicana Literature. Austin: University of Texas Press.

Sandoval, Chela. 2013. Methodology of the Oppressed. Minneapolis: University of Minnesota Press, vol. 18.

Satcher, David. 2000. Mental health: A report of the surgeon general-executive summary. Professional Psychology: Research and Practice 31: 5. [CrossRef]

Semega, Jessica L., Kayla R. Fontenot, and Melissa A. Kollar. 2017. Income and poverty in the United States: 2016. Current Population Reports. Washington, DC: U.S. Government Printing Office, pp. 60-259.

Silver, Alexis. 2014. Families across borders: The emotional impacts of migration on origin families. International Migration 52: 194-220. [CrossRef]

Smith, Linda Tuhiwai. 1999. Decolonizing Methodologies: Research and Indigenous Peoples. London: Zed Books.

Soriano Hernández, Silvia. 1994. Lucha y Resistencia Indígena en el México Colonial. Mexico City: Universidad Nacional Autónoma de México.

Sotero, Michelle. 2006. A conceptual model of historical trauma: Implications for public health practice and research. Journal of Health Disparities Research and Practice 1: 93-108.

Stepler, Renee, and Anna Brown. 2016. Statistical portrait of Hispanics in the United States. Pew Research Center 19.Available online: https: / / www.pewresearch.org/hispanic/2016/04/19/2014-statistical-information-on-hispanics-in-united-states/ (accessed on 29 September 2020).

Stevens, Sally, Rosi Andrade, Josephine Korchmaros, and Kelly Sharron. 2015. Intergenerational trauma Among substance-using Native American, Latina, and White mothers living in the southwestern United States. Journal of Social Work Practice in the Addictions 15: 6-24. [CrossRef]

Suleman, Shazeen, Kent D. Garber, and Lainie Rutkow. 2018. Xenophobia as a determinant of health: An integrative review. Journal of Public Health Policy 39: 407-23. [CrossRef]

Szreter, Simon. 2003. The population health approach in historical perspective. American Journal of Public Health 93: 421-31. [CrossRef] [PubMed]

Talebreza-May, Jon. 2015. Cultural trauma in the lives of men in northern New Mexico. The Journal of Men's Studies 23: 119-32. [CrossRef]

Tedeschi, Richard G., and Lawrence G. Calhoun. 1996. The posttraumatic growth inventory: Measuring the positive legacy of trauma. Journal of Traumatic Stress 9: 455-71. [CrossRef] [PubMed] 
Thompson, Wallace. 1921. The People of México: Who They Are and How They Live. New York:: Harper \& Brothers.

Tuck, Eve, and K. Wayne Yang. 2012. Decolonization is not a metaphor. Decolonization: Indigeneity, Education E Society 1: 1.

US Census Bureau. 2000. Census 2000; Suitland: US Census Bureau.

Valverde, Eduardo E., Thomas Painter, James D. Heffelfinger, Jeffrey D. Schulden, Pollyanna Chavez, and Elizabeth A. DiNenno. 2015. Migration patterns and characteristics of sexual partners associated with unprotected sexual intercourse among hispanic immigrant and migrant women in the united states. Journal of Immigrant and Minority Health 17: 1826-33. [CrossRef]

Van Dijk, Teun A. 1983. Discourse analysis: Its development and application to the structure of news. Journal of Communication 33: 20-43. [CrossRef]

Van Dijk, Teun A. 2004. Knowledge, discourse and scientific communication. Paper presented at 8th International Public Communication of Science and Technology Conference, Barcelona, Spain, June 3-6, pp. 1-3.

Van Dijk, Teun A. 2006. Discourse, context and cognition. Discourse Studies 8: 159-77. [CrossRef]

Van Dijk, Teun A. 2019. Racismo y Discurso en América Latina. Barcelona, Spain: Editorial Gedisa, vol. 311008.

Van Ee, Elisa, and Rolf J Kleber. 2013. Growing up under a shadow: Key issues in research on and treatment of children born of rape. Child Abuse Review 22: 386-97. [CrossRef]

Varcoe, Colleen, Annette J. Browne, and Laurie Cender. 2014. Promoting social justice and equity by practicing nursing to address structural inequities and structural violence. Philosophies and Practices of Emancipatory Nursing: Social Justice as Praxis 11: 266-84.

Vargas-Hernández, José Guadalupe. 2005. Movimientos sociales para el reconocimiento de los movimientos indígenas y la ecología política indígena. Ra Ximhai 1: 453-70. [CrossRef]

Vasconcelos, José. 1993. La Raza Cósmica. Madrid: CESLA, Centro de Estudios Latinoamericanos, Universidad.

Vasconcelos, José, and Luis González. 1944. Breve Historia de México; México DF: Editorial Polis.

Vasquez, Melba J. T. 1998. Latinos and violence: Mental health implications and strategies for clinicians. Cultural Diversity and Mental Health 4: 319. [CrossRef]

Vega, William A., Richard L. Hough, and Manuel R. Miranda. 1985. Modeling Cross-Cultural Research in Hispanic Mental Health. Bethesda: National Institute of Mental Health.

Vigil, James, and Felipe Lopez. 2004. Race and ethnic relations in Mexico. Journal of Latino/Latin American Studies 1: 49-74. [CrossRef]

Viruell-Fuentes, Edna A., Patricia Y. Miranda, and Sawsan Abdulrahim. 2012. More than culture: Structural racism, intersectionality theory, and immigrant health. Social Science \& Medicine 75: 2099-106.

Wallace, Leite Paula, and Ximena Castañeda. 2010. Migration and Health: Mexican Immigrant Women in the United States. Joint Report. México DF: Consejo Nacional de Populación de México.

Wallerstein, Nina, and Bonnie Duran. 2010. Community-based participatory research contributions to intervention research: The intersection of science and practice to improve health equity. American Journal of Public Health 100: S40-S46. [CrossRef]

Walters, Karina, Selina Mohammed, Teresa Evans-Campbell, Ramona Beltrán, David Chae, and Bonnie Duran. 2011. Bodies do not just tell stories, they tell histories. Du Bois Review 8: 179-89. [CrossRef] [PubMed]

Walters, Karina, and Jane M. Simoni. 2002. Reconceptualizing Native women's health: An “indigenist" stress-coping model. American Journal of Public Health 92: 520-24. [CrossRef] [PubMed]

Walters, Karina L., Michelle Johnson-Jennings, Sandra Stroud, Stacy Rasmus, Billy Charles, Simeon John, James Allen, Joseph Keawe'aimoku Kaholokula, Mele A. Look, Māpuana de Silva, and et al. 2020. Growing from our roots: Strategies for developing culturally grounded health promotion interventions in american indian, alaska native, and native hawaiian communities. Prevention Science 21: 54-64. [CrossRef]

Watt, Diane. 2007. On becoming a qualitative researcher: The value of reflexivity. Qualitative Report 12: 82-101.

Weaver, Hilary N. 2001. Indigenous identity: What is it, and who really has it? American Indian Quarterly 25: 240-55. [CrossRef]

Weaver, Thomas. 1992. Los Indios del Gran Suroeste de los Estados Unidos: Veinte Siglos de Adaptaciones Culturales. Editorial MAPFRE.

Weinick, Robin M., Elizabeth A. Jacobs, Lisa Cacari Stone, Alexander N. Ortega, and Helen Burstin. 2004. Hispanic healthcare disparities: Challenging the myth of a monolithic Hispanic population. Medical Care 42: 313-20. [CrossRef]

Wells, Karen. 2017. What does a republican government with donald trump as president of the usa mean for children, youth and families? Children's Geographies 15: 491-97. [CrossRef]

Whitbeck, Les B., Gary W. Adams, Dan R. Hoyt, and Xiaojin Chen. 2004. Conceptualizing and Measuring Historical Trauma Among American Indian People. American Journal of Community Psychology 33: 119-30. [CrossRef]

White, Michael. 1998. Narrative therapy. In Workshop Presented at Narrative Therapy Intensive Training. Dulwich Centre: Adelaide, Australia.

Wiegand, Phil C., and Jay C. Fikes. 2004. Sensacionalismo y etnografía: El caso de los Huicholes de Jalisco. Relaciones. Estudios de Historia y Sociedad 25: 98.

Williams-Washington, Kristin N., and Chmaika P. Mills. 2018. African american historical trauma: Creating an inclusive measure. Journal of Multicultural Counseling and Development 46: 246-63. [CrossRef]

Yehuda, Rachel, Sarah L. Halligan, and Robert Grossman. 2001. Childhood trauma and risk for ptsd: Relationship to intergenerational effects of trauma, parental ptsd, and cortisol excretion. Development and Psychopathology 13: 733-53. [CrossRef]

Yehuda, Rachel, James Schmeidler, Milton Wainberg, Karen Binder-Brynes, and Tamar Duvdevani. 1998. Vulnerability to posttraumatic stress disorder in adult offspring of Holocaust survivors. American Journal of Psychiatry 155: 1163-71. [CrossRef] 
Zacharias, Steffi. 2006. Mexican Curanderismo as Ethnopsychotherapy: A qualitative study on treatment practices, effectiveness, and mechanisms of change. International Journal of Disability, Development and Education 53: 381-400. [CrossRef]

Zentella, Yoly. 2004. Land loss among the Hispanos of Northern New México: Unfinished psychological business. Journal of Human Behavior in the Social Environment 9: 83-103. [CrossRef]

Zentella, Yoly. 2009. Developing a Multi-Dimensional Model of Hispano Attachment to and Loss of Land. Culture E Psychology 15: 181-200.

Zentella, Yoly. 2014. No lloro pero me acuerdo: Hidden voices in a psychological model. Journal of Progressive Human Services 25: 181-213. [CrossRef]

Zhang, Xiao, Ana P. Martinez-Donate, Jenna Nobles, Melbourne F. Hovell, Maria Gudelia Rangel, and Natalie M. Rhoads. 2015. Substance use across different phases of the migration process: A survey of Mexican migrants flows. Journal of Immigrant and Minority Health 17: 1746-57. [CrossRef]

Zizumbo-Colunga, Daniel, and I. Martínez. 2017. Is Mexico a Post-Racial Country? Inequality and Skin Tone across the Americas. México: Center for Research and Teaching in Economics (CIDE), Topical Brief, vol. 31.

Zúñiga, María Luisa, Pedro Lewin Fischer, Debra Cornelius, Wayne Cornelius, Shira Goldenberg, and David Keyes. $2014 . \quad$ A transnational approach to understanding indicators of mental health, alcohol use and reproductive health among Indigenous Mexican migrants. Journal of Immigrant and Minority Health 16: 329-39. [CrossRef] [PubMed] 